بررسى اثر روش آبيارى بر شاخص برداشت و بهرهورى آب دو رقم كندم در شرايط استفاده از كود ازته

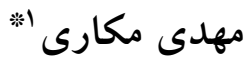

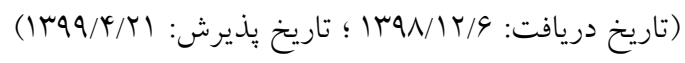

جكيده

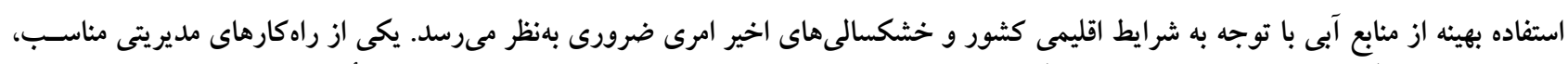

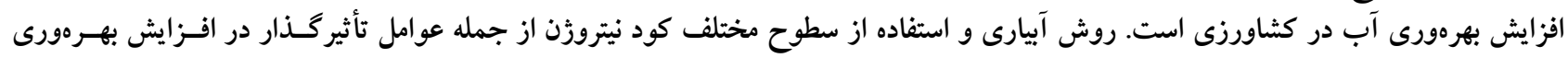

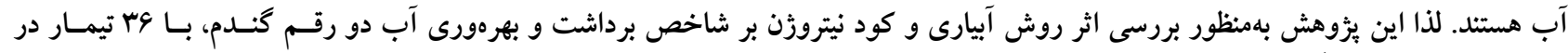

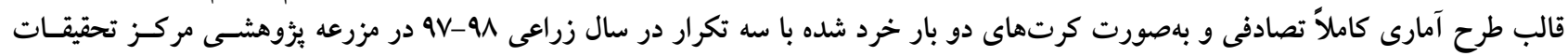

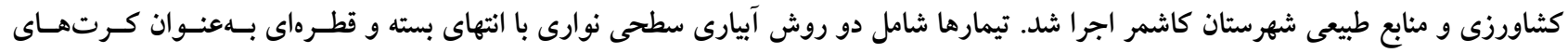

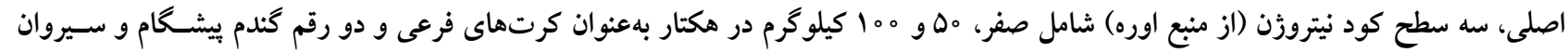

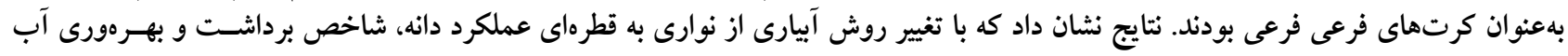

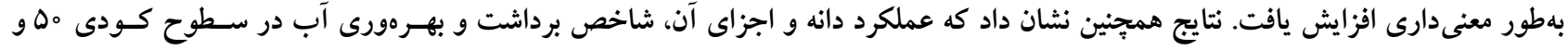

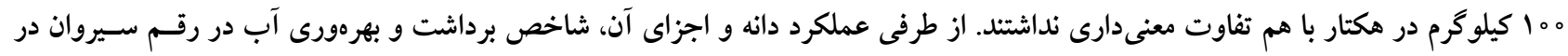

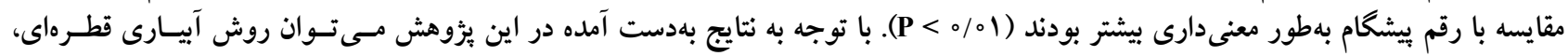

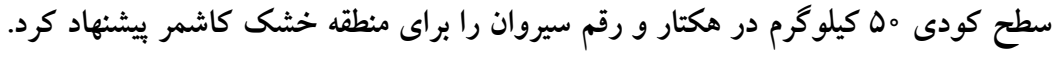

وازههاى كليدى: عملكرد دانه، بهرهورى آب، شاخص برداشت

1. كروه علوم و مهندسى آب، مركز آموزش عالى كاشمر، ايران

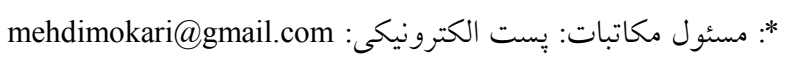


جذب نيتروزن توسط دانه و توليد دانه و بروتئين آن از اهميـت

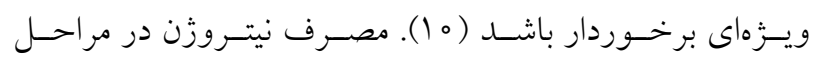

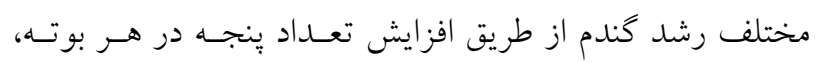

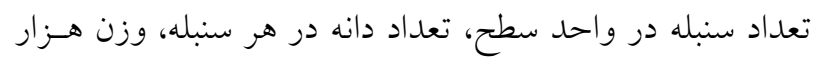

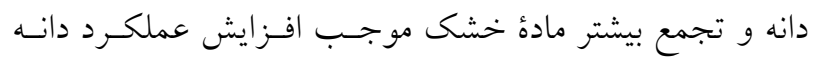
مىشود (TQ).

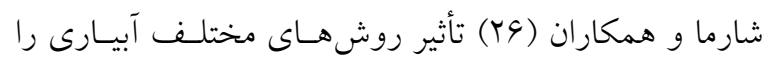

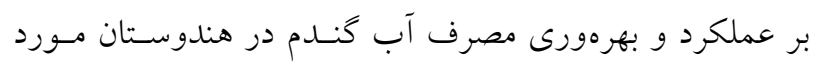

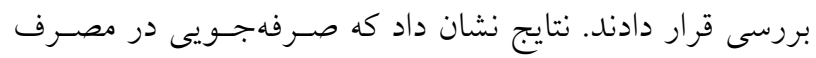

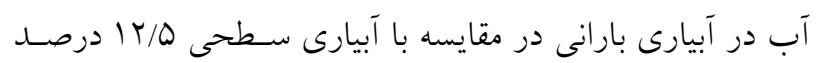

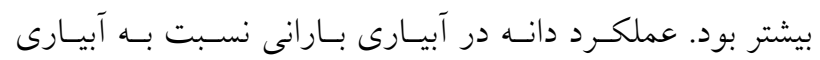

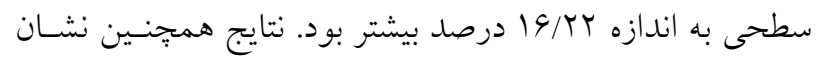

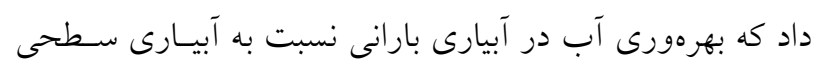

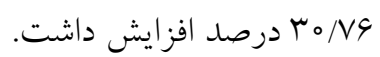

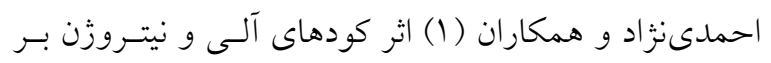

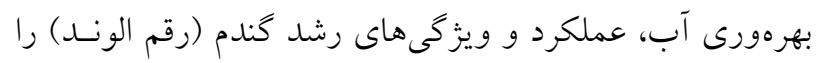

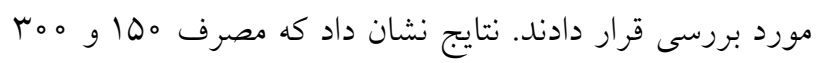

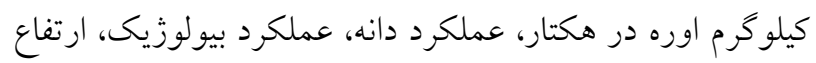

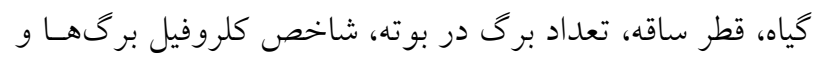

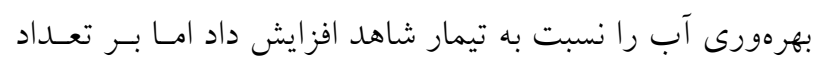

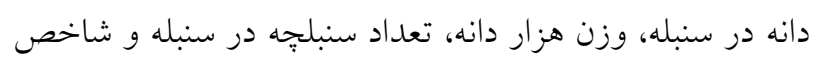
برداشت اثر معنى دارى نداشت.

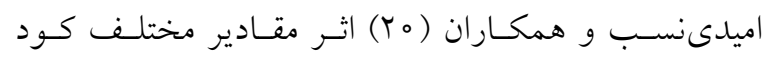

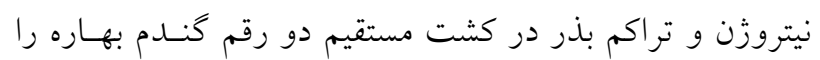

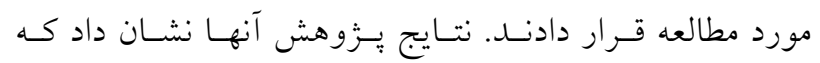

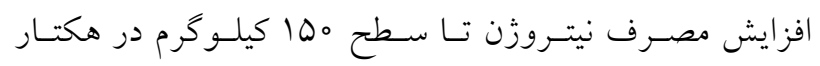

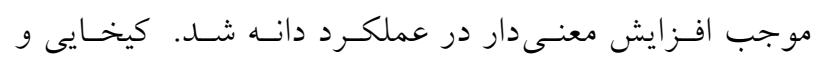

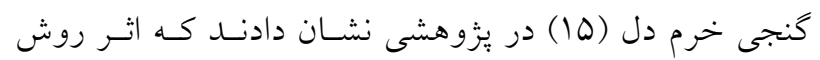

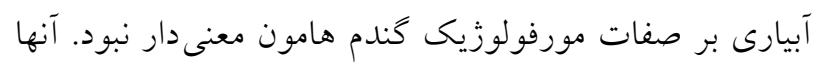

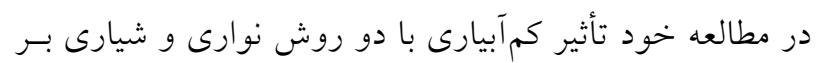

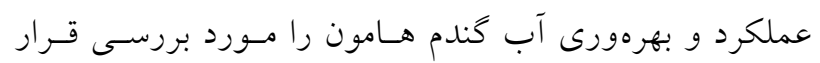

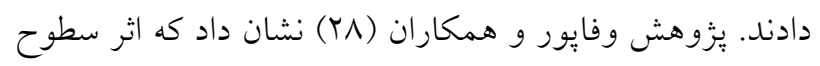

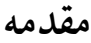

كُندم (Triticum aestivum L.) مهم ترين گيـاه زراعسى و اولـين غله دانهاى دنيـا اسـت كـه در مسـاحت وسـيعى از زمهين هـاى

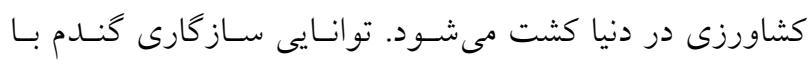
اقليمهاى مختلف به حدى است كه در سراسر كره زمين قابليت

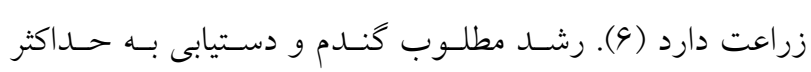

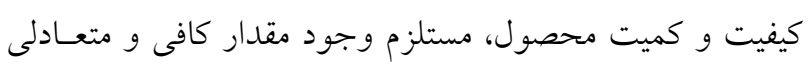

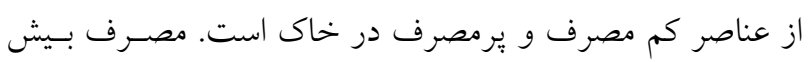

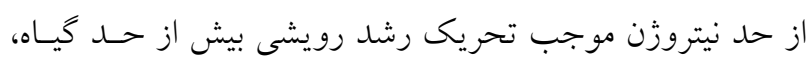

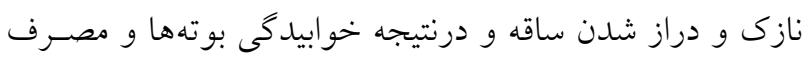

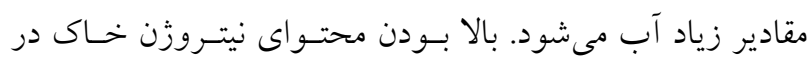

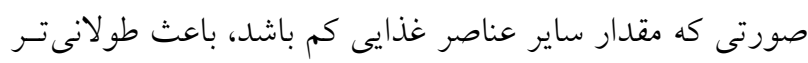

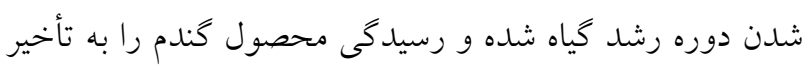

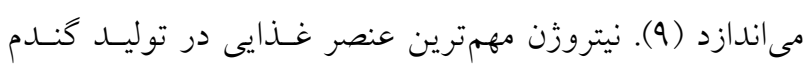

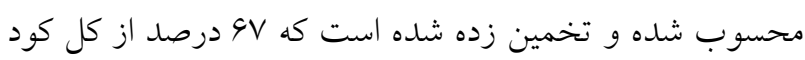
مصرفى غلات در سطح جهـان، مربـوط بـه كودهـاى نيتـروزن

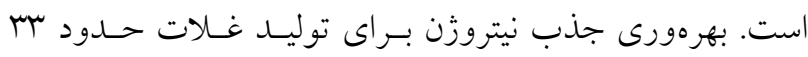

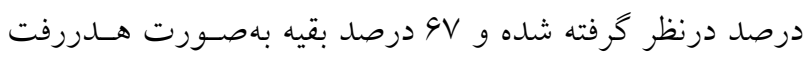

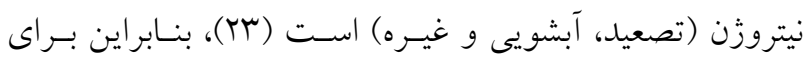

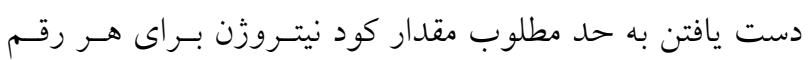

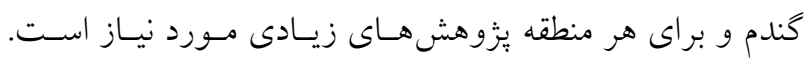

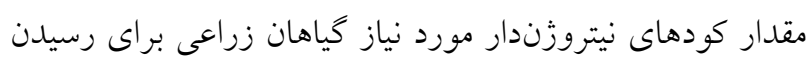

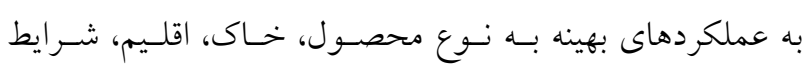
زراعى و سن فيزيولوزيك كياه وابسته است، بهطورى كه ميـزان

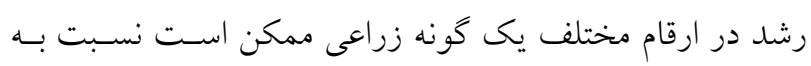
يكى ميزان مشخص نيتروزن، متفاوت باشد (V).

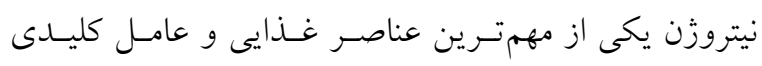

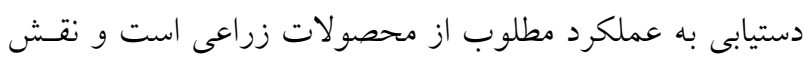

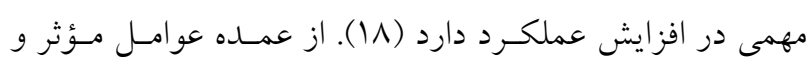
ههم بر خواص كمى و كيفى كندم توزيع متعادل كودها بـهويـزّه

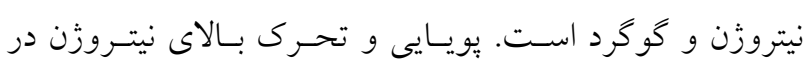

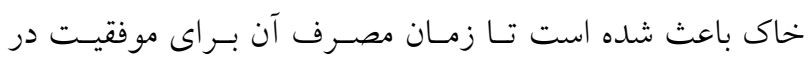




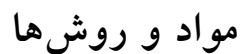

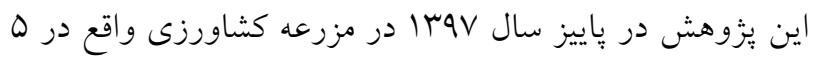

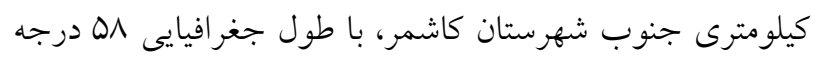

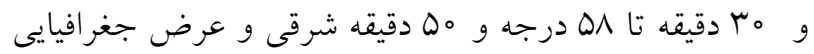

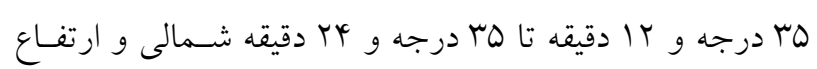

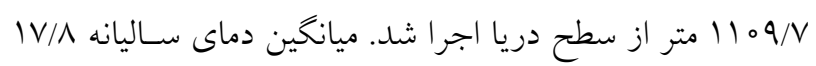

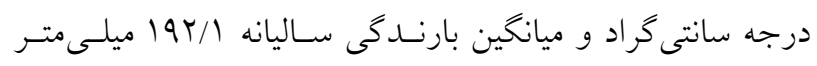

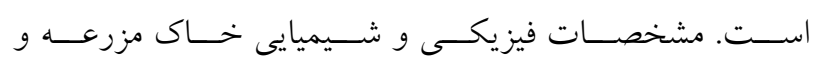

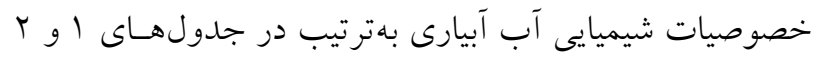

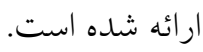

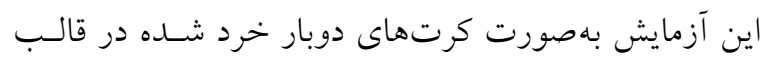

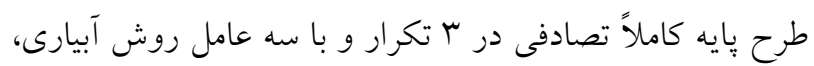

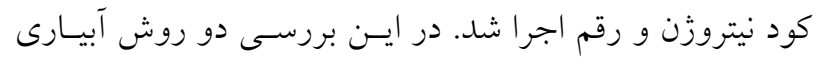

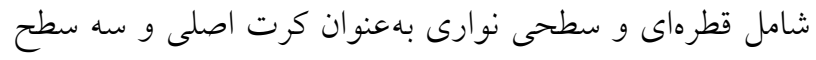

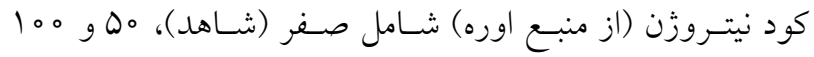

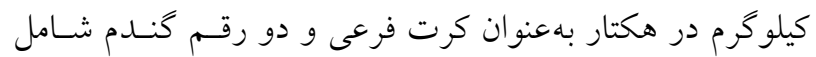
يبيشام و سيروان بهعنوان كرت فرعى فرعى مورد استفاده قـرار

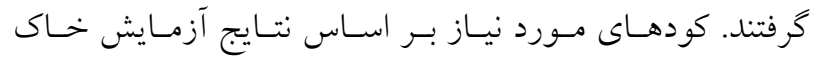

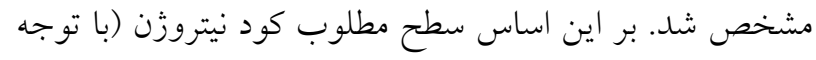

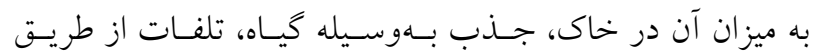

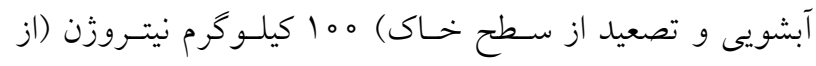

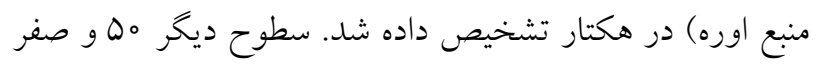
كيلوكرم بر اين اساس اختيار شد كه هدف بروسى عكس دنس العمل كياه به تنش نيتروزن بودم.

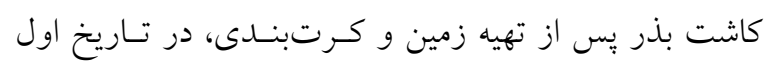

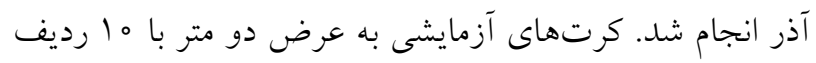

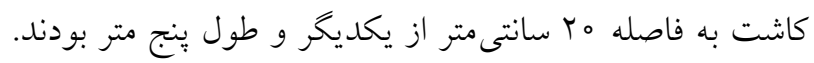

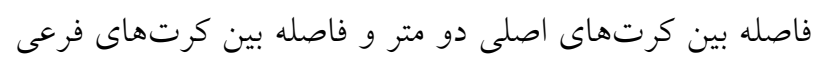

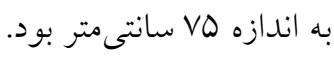

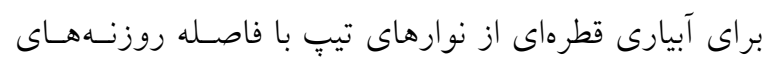

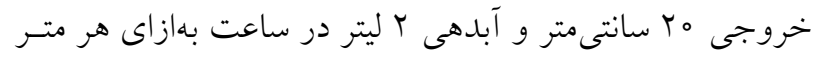

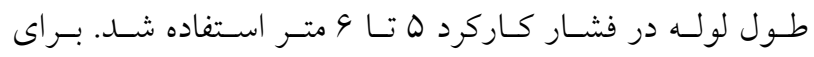

مختلف كود بر ارتفاع بوته، تعـداد دانسه در سـنبله، وزن هـزار

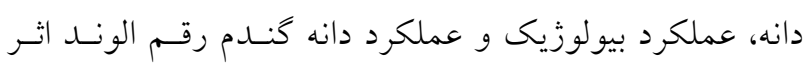

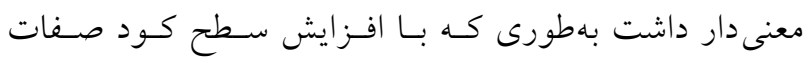
مورفولوزيك مذكور افزايش يافتند. نتيجه مطالعه آنها همجنِين نشان داد كه سطوح مختلـف كـود بــر شـاخص برداشـت اثـر

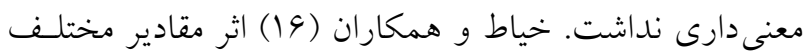

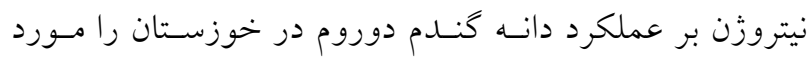

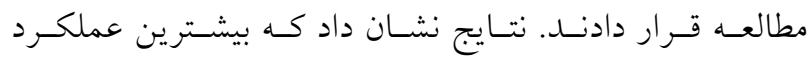

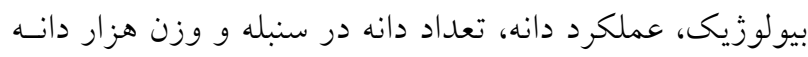
در تيمار كاربرد ها كيلوگرم نيتـروزن خـالص در هكتـار بـهـ

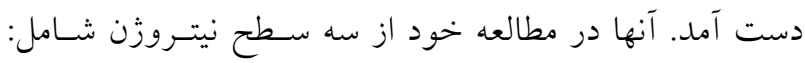

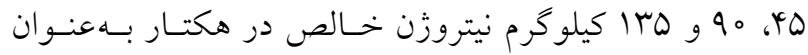
عامل اصلى و سـهـ رقـم كَنـدم شـامل يـاواروس، شـوا و S78 بهنوان عامل فرعى استفاده كردند.

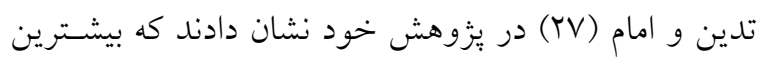
شاخص سطح برى، ارتفـاع بوتسه و عملكــــد دانـه از بـالاترين

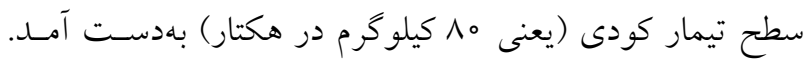

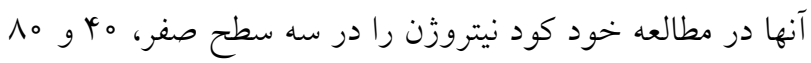

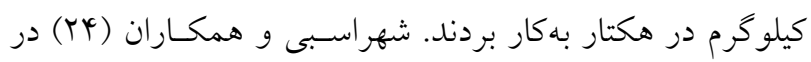

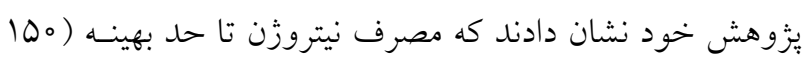

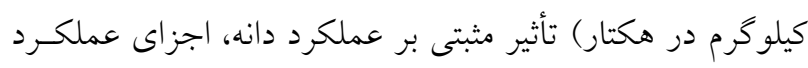

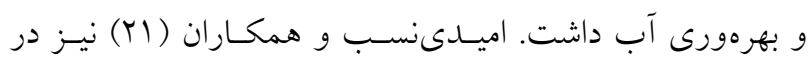

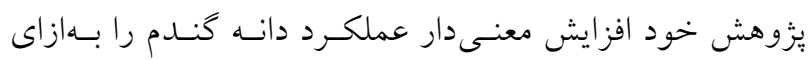

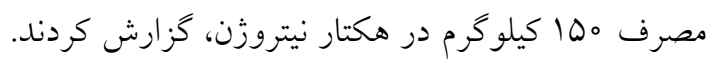

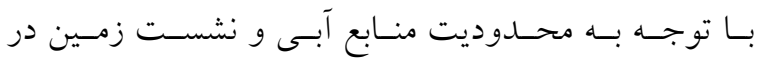

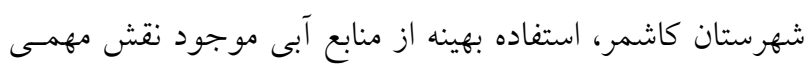

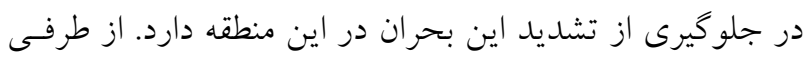

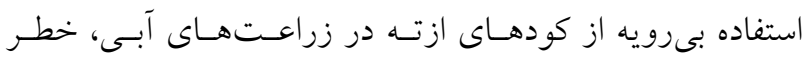

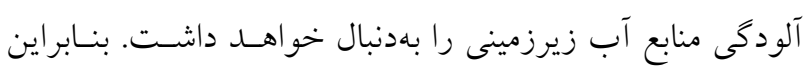

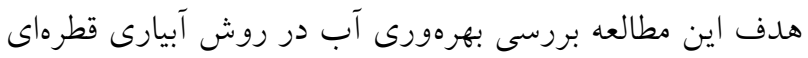
و سطحى نوارى و همجنين حد مطلوب استفاده از كود ازتسه در زراعت گندم در شهرستان كاشمر بود. 
جدول ا. خصوصيات فيزيكى و شيميايى خاك مزرعه

\begin{tabular}{|c|c|c|c|c|c|c|c|}
\hline \multicolumn{8}{|c|}{ درصد رطوبت وزنى } \\
\hline جرم مخصوص ظاهرى ( $\left.{ }^{-3}\right)$ & بافت خاى & PWP & $\mathrm{FC}$ & $\mathrm{pH}$ & $\mathrm{EC}\left(\mathrm{dS} \mathrm{m} \mathrm{m}^{-1}\right)$ & $(\%) \mathrm{OC}$ & عمق خاى (cm) \\
\hline $1 / 90$ & لو لوى رسى & Ir & rt & $V / 4$ & $1 / 1$ & $0 / 90$ & $\circ-\mu_{0}$ \\
\hline
\end{tabular}

جدول r. - خصوصيات شيميايى آب آبيارى

\begin{tabular}{|c|c|c|c|c|c|c|}
\hline \multirow{2}{*}{$\mathrm{pH}$} & \multirow{2}{*}{$\begin{array}{l}\text { مواد محلول } \\
\text { TDS (ppm) }\end{array}$} & \multicolumn{4}{|c|}{ غلظت كاتيونها و آنيونها (meqL-1) } & \multirow{2}{*}{$\mathrm{EC}\left(\mathrm{dS} \mathrm{m} \mathrm{m}^{-1}\right)$} \\
\hline & & $\mathrm{Cl}$ & $\mathrm{HCO}^{3-}$ & $\mathrm{Ca}^{2+}+\mathrm{Mg}^{2+}$ & $\mathrm{Na}^{+}$ & \\
\hline$V / \Lambda$ & M。 & $1 / 1$ & $r / 4$ & $r / 9$ & $1 / r$ & o/AY \\
\hline
\end{tabular}

دور آبيارى براى آبيارى قطرهاى ب روز و براى آبيارى نــوارى V روز بر اساس عرف منطقه درنظر كرفته شد. براى محاسبه عمق خالص آبيارى در آبيارى نوارى از رابطه (r) و در آبيارى قطـره اى از رابطه (Y) استفاده شد (Y):

$\mathrm{d}_{\mathrm{n}}=\sum_{\mathrm{i}=1}^{7} \mathrm{ET}_{\mathrm{Ci}}-\mathrm{P}_{\mathrm{e}}$

$\mathrm{d}_{\mathrm{n}}=\mathrm{K}_{\mathrm{r}} \times\left(\sum_{\mathrm{i}=1}^{3} \mathrm{ET}_{\mathrm{Ci}}-\mathrm{P}_{\mathrm{e}}\right)$

كه در روابط فوق، dn عمق خالص آبيارى (mm و ضـريب مربوط به سطح سايه اندازى گياه (يعنى درصد بوشـش گيـاهى نسبت به كل سطح مزرعه) در آبيارى قطرهاى است.

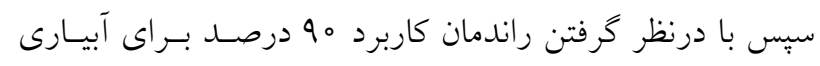
قطرهاى و هو درصد براى آبيارى نوارى، عمق ناخالص آبيـارى

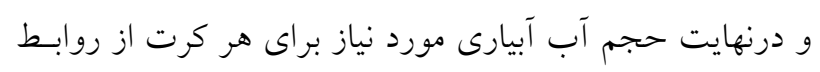
زير محاسبه شد:

$\mathrm{d}_{\mathrm{g}}=\frac{\mathrm{d}_{\mathrm{n}}}{\mathrm{E}_{\mathrm{a}}}$

$\mathrm{V}=\mathrm{d}_{\mathrm{g}} \times \mathrm{A}$

كه در روابط فوق، dd عمق ناخالص آبيارى (mm)، E رانـدمان كاربرد، A مساحت هر كرت (مترمربع) و V حجـم آب آبيـارى برحسب ليتر است. بعــ از عمليـات كاشـت اولـين آبيـارى در

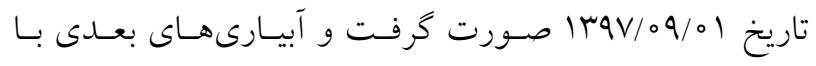
رعايت دور آبيارى در هر دو روش آبيارى قطرهاى و نــوارى تـا

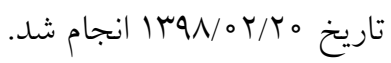

اندازهگيرى فشار و تنظيم مقدار حجم آب ورودى به هر يك از تيمارهاى آبيارى يس از عبور آب از صافى، از شيرفلكه، كتــور و فشارسنج استفاده شد.

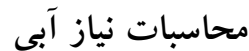
براى محاسبه تبخيـر و تعـرق مرجـع از فرمـول يــنمن مانتيـث

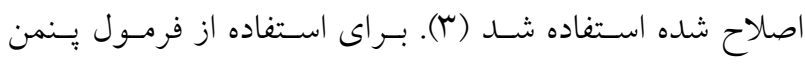
مانتيث اصلاح شده، بارامترهاى مورد نياز از جمله دماى بيشـينه و كمينه، رطوبت نسبى بيشينه و كمينه، سـرعت بـاد و سـاعات آفتابى بهصورت روزانه از ايستخاه همديدى كاشمر اخذ و تبخير و تعرق گياه مرجع محاسبه شد. ستبس نياز آبى گيـاه بـا اعمـال ضريب گياهى گندم در مراحل مختلف رشد (اقتبـاس از نشـريه وه فائو) و با استفاده از رابطه زير تعيين شد: $\mathrm{ET}_{\mathrm{C}}=\mathrm{K}_{\mathrm{C}} \times \mathrm{ET}_{0}$

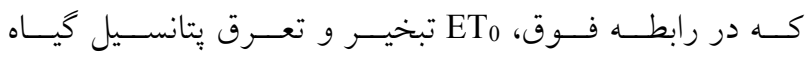
مرجع (ميلىمتر در روز)، ETC نياز آبى گياه (ميلىمتر بر روز) و

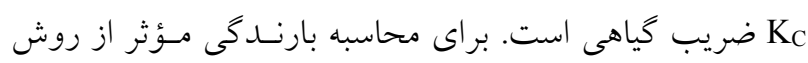
ارائه شده توسط سازمان حفاظت خاك امريكـا (SCS) اسـتفاده

$\mathrm{P}_{\mathrm{e}}=\frac{\mathrm{P}_{\mathrm{t}} \times\left[125-\left(0.2 \times \mathrm{P}_{\mathrm{t}}\right)\right]}{125}$

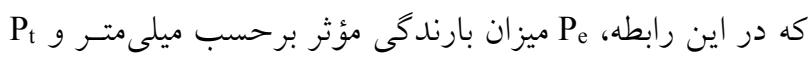
باران كل ماهانه (mm) است. 
ارتفاع گياه مربوط به سطح كود نيتروزن م 10 كيلـوكرم در هكتـار و

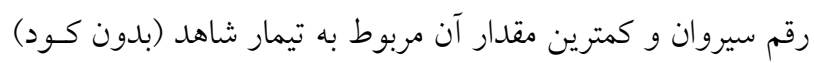
و رقم بيشگام بود (شكل () كه اختلاف معنى دارى با هـم داشـتند.

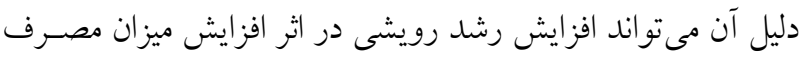
نيتروزن باشد. در شر ايطى كه رطوبت مطلوب باشد، نيتروزن خيلى

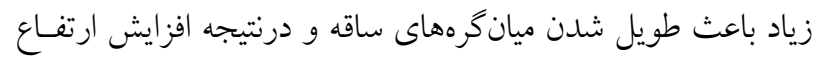

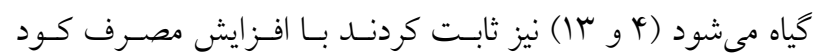

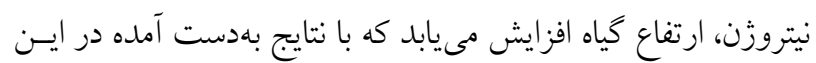
يُزوهش مطابقت داشت. مك مستر و همكاران (19) نيز اظهار داشتند كه ارتفاع ساقه

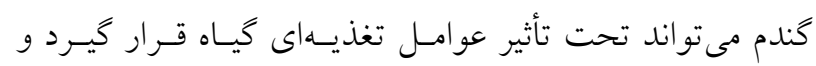

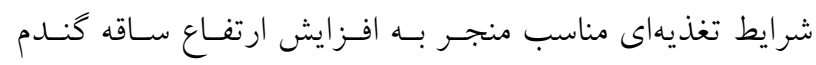

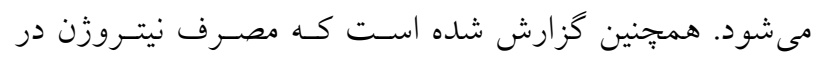

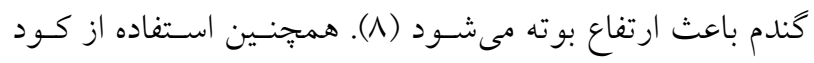

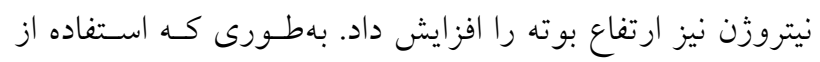

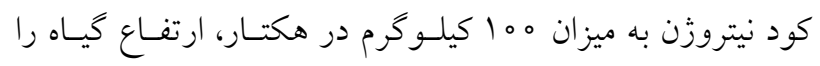
ا I/D/ه سانتى متر افزايش داد.

\section{عملكرد بيولوزيك}

عملكرد بيولوزيك به كل ماده خشك توليد شده (دانسه، سـاقه و

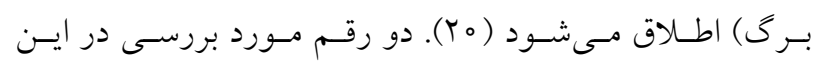

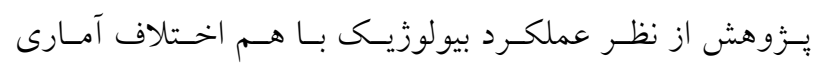

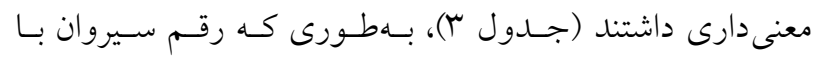

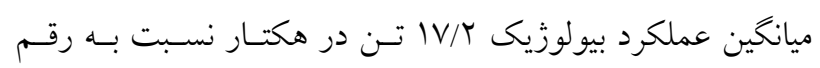

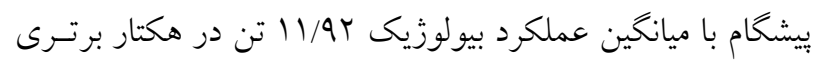

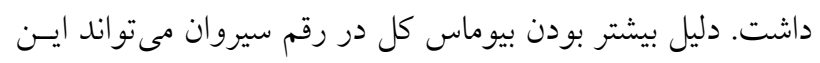

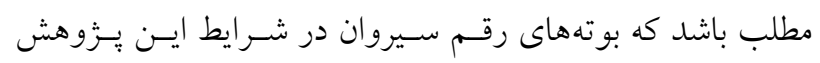

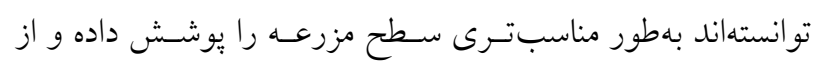
عوامل محيطى به نحو مطلوبترى استفاده كنــد، درنتيجـه ميـزان عملكرد بيولوزيكى بيشترى در واحح سطح نيـز توليـد كنـــ (Y) (Y).

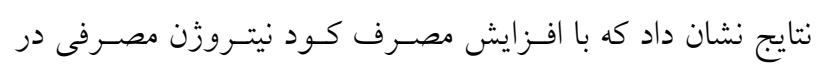

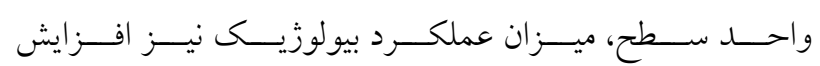

عمليات برداشت نهـايى بـراى تمـامى تيمارهـا زمـانى صـورت

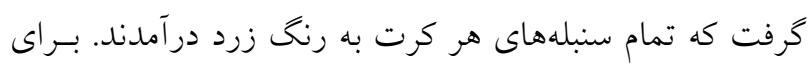
اين منظور از وسط هر كرت با رعايت حاشسيه، سـطحى معـادل

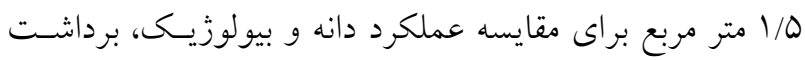
شد. بهمنظور محاسبه عملكرد دانه، كل سنبله هاى برداشت شــده

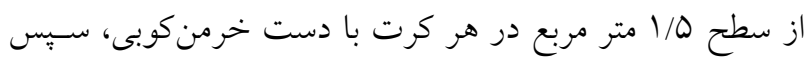

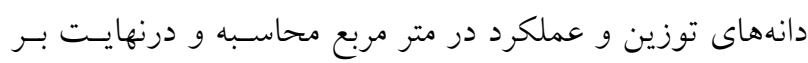

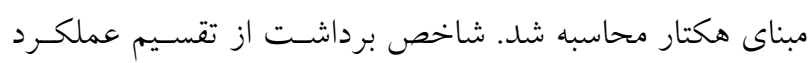

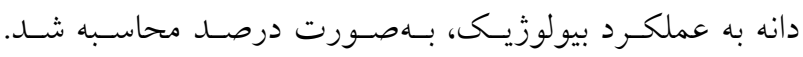

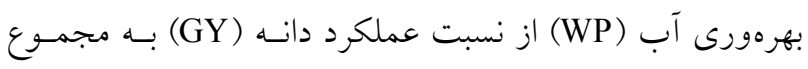

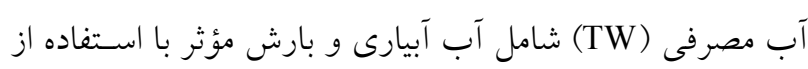
رابطه زير محاسبه شد (IV):

$\mathrm{WP}=\frac{\mathrm{GY}}{\mathrm{TW}}$

كه در اين رابطه، WP بهرهورى آب (كيلـوكرم بـر مترمكعـب)،

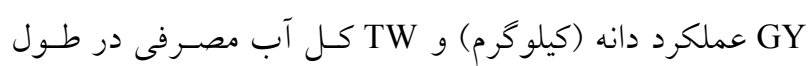

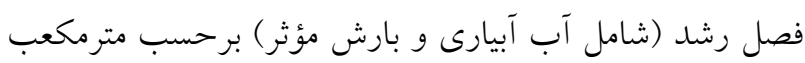
هستند. بهمنظور تعيين صفاتى مانند ارتفاع بوته، طول سنبله و تعداد

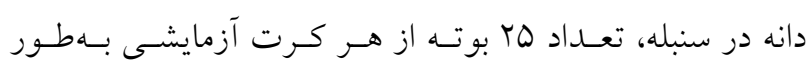

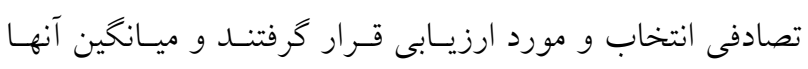

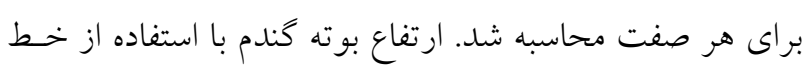

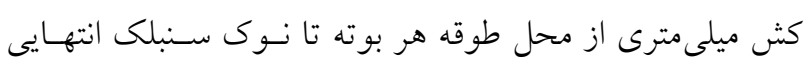

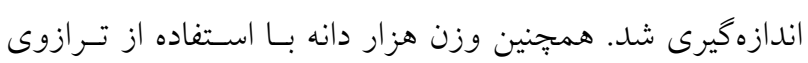

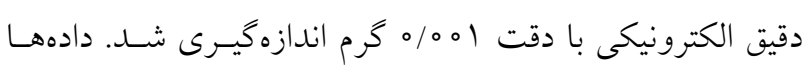

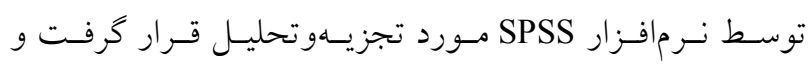

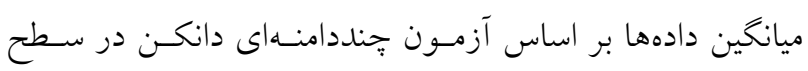
احتمال بينج درصد مقايسه شدند.

\section{نتايج و بحث ارتفاع گياه} نتايج جدول تجزيه واريانس (جدول ب) نشان داد كه اثر متقابل رقم و سطوح مختلف كود نيتروزن بر ارتفاع گياه معنى دار بود. بيشترين 


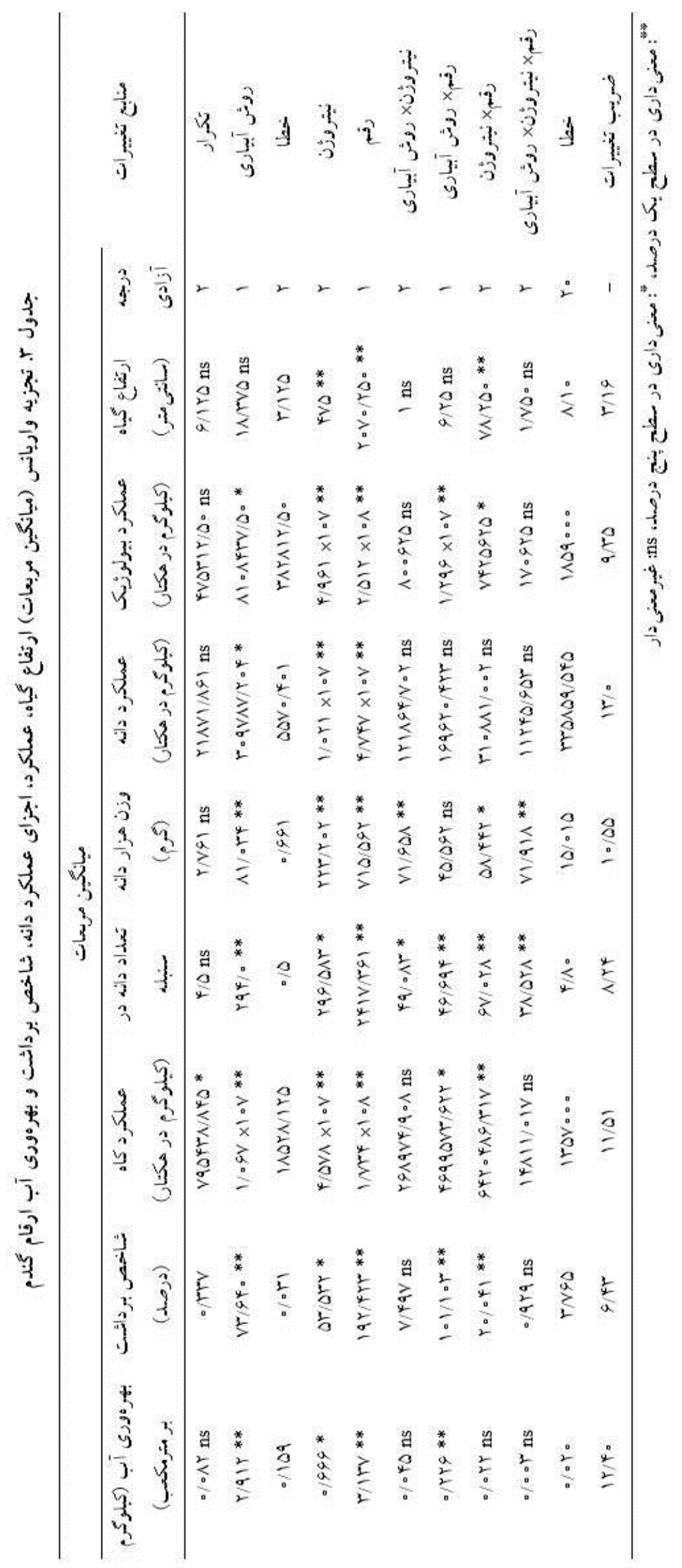


مقايسه اثرات ساده عامل روشهـاى مختلـف آبيـارى و مقــادير

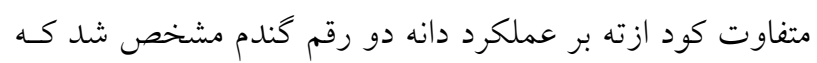

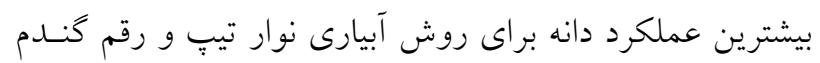

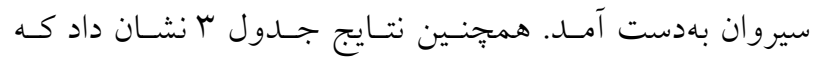

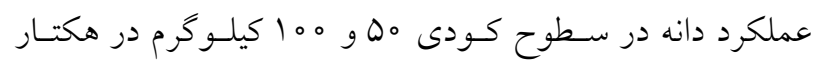
تفاوت معنى دارى نداشت. بيشترين عملكـرد دانـه بــراى تيمـار كودى ه 10 كيلوكرم در هكتار و كمترين مقدار آن بـراى تيمـار

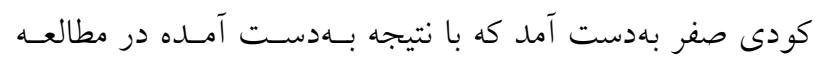
تدين و امـام (YV) همخـوانى داشـت. همجنــين نتيجـه مطالعـه

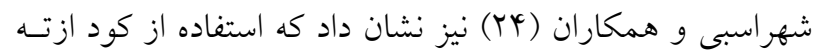

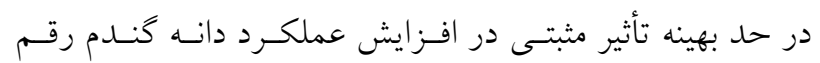
سيروان در استان فارس داشـت. نتيجـه مطالعـه احمـــىنـزاد و همكاران (1) نيز افزايش معنى دار عملكرد دانه كُندم راد در تيمار

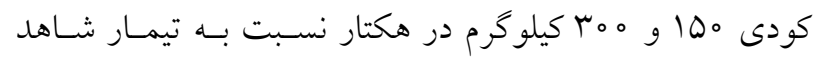

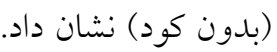

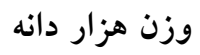

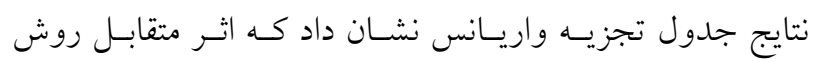

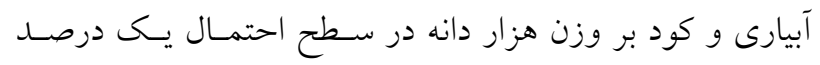

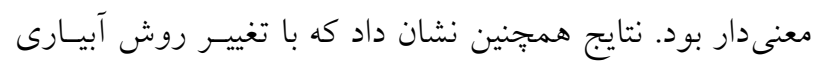

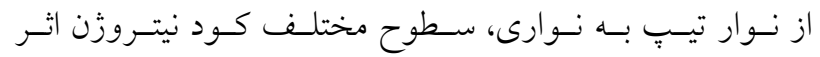

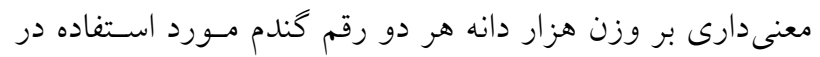

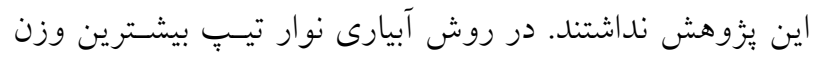

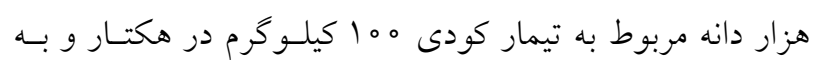

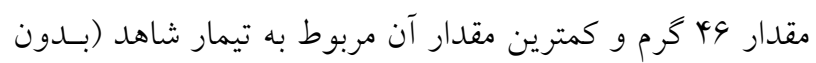

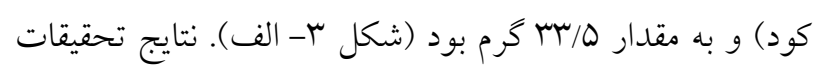

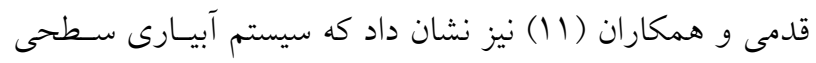

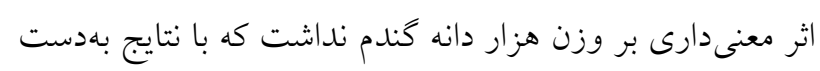
آمده در اين يزوهش مطابقت داشت.

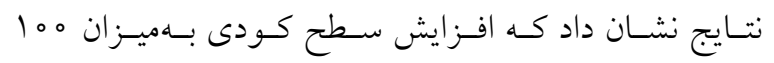

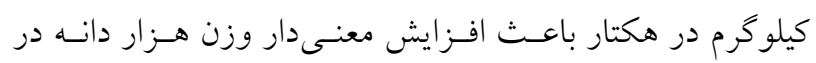

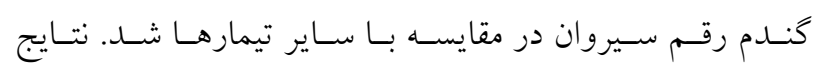

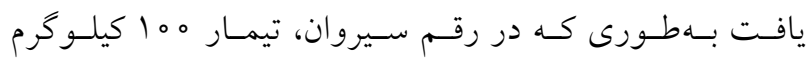

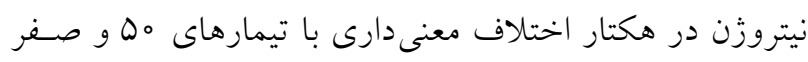

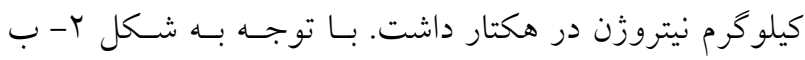

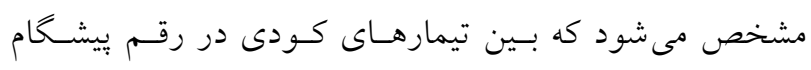

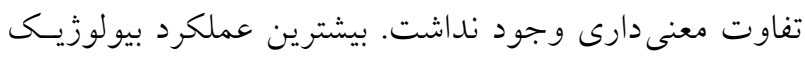

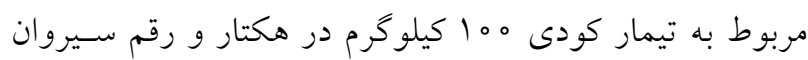

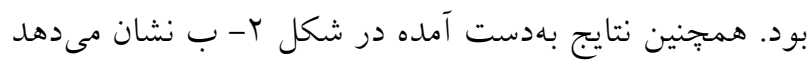

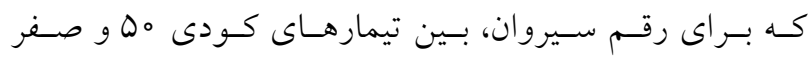

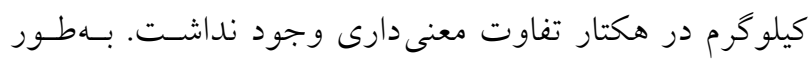

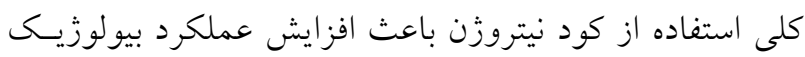

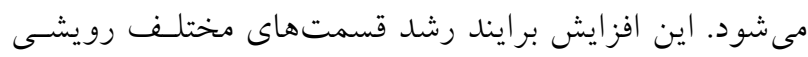
در اثر مصرف كود نيتروزن است. مصرف كود نيتروزن بهعلت

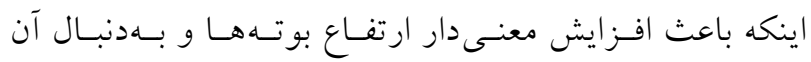

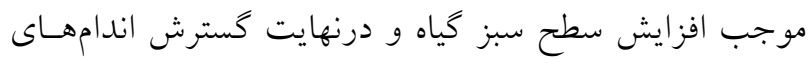

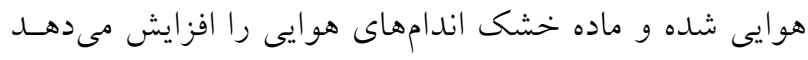

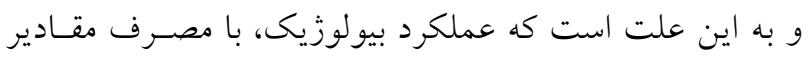

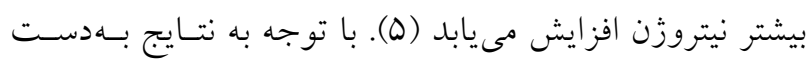

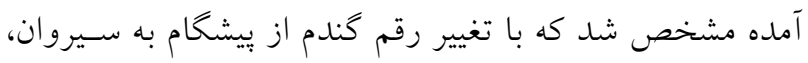

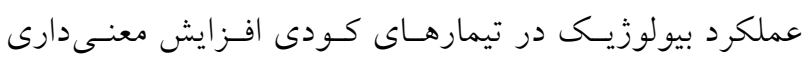

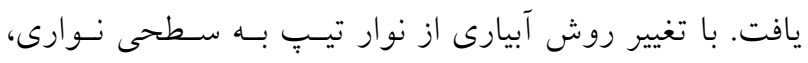

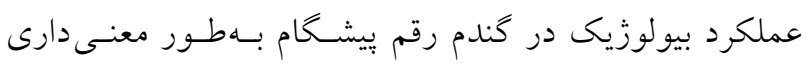

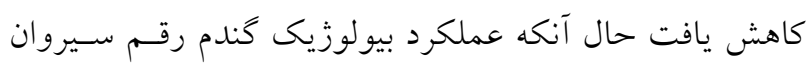
در هر دو روش آبيارى تفاوت معنسى دارى نداشـت. بيشـترين

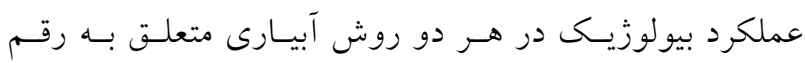

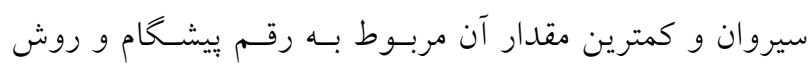

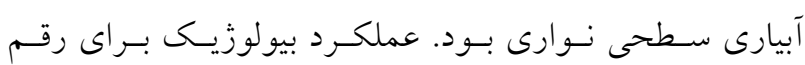

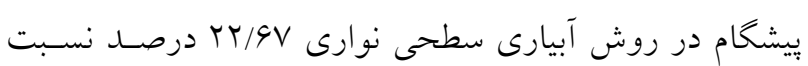

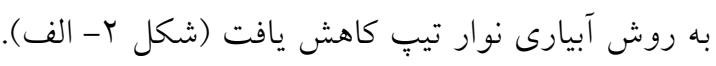

عملكرد دانه نتايج جدول تجزيه واريانس (جدول r) نشان داد كه اثر متقابـل

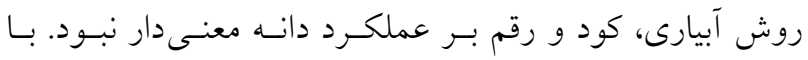



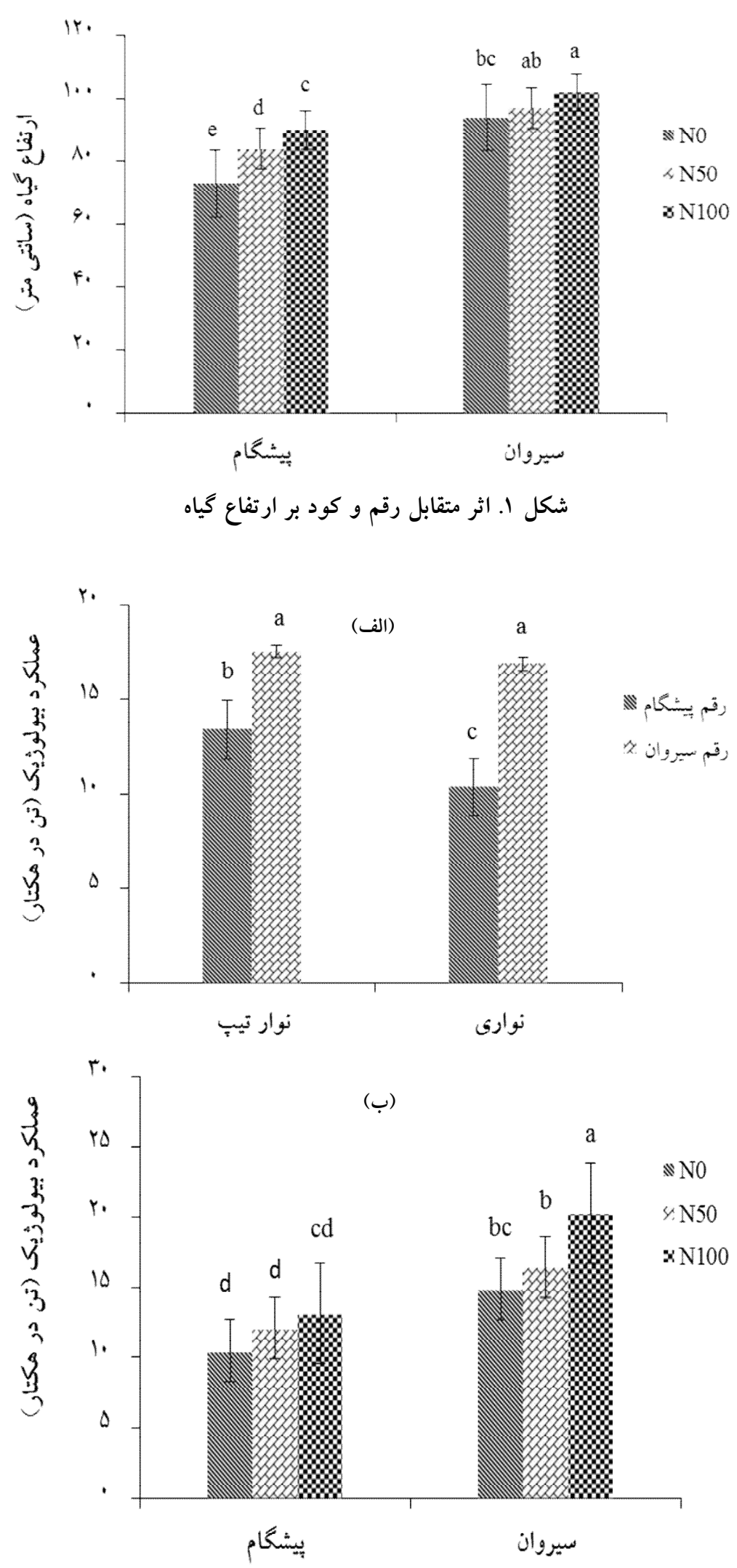

شكل r ـ اثر متقابل: الف) روش آبيارى و رقم و ب) كود و رقم بر عملكرد بيولوزيك

(حروف مشترى در هر يك از ستوذها بيانكر عدم معنىدارى مقايسهُ ميانگينها در سطح احتمال ينج درصد است. 

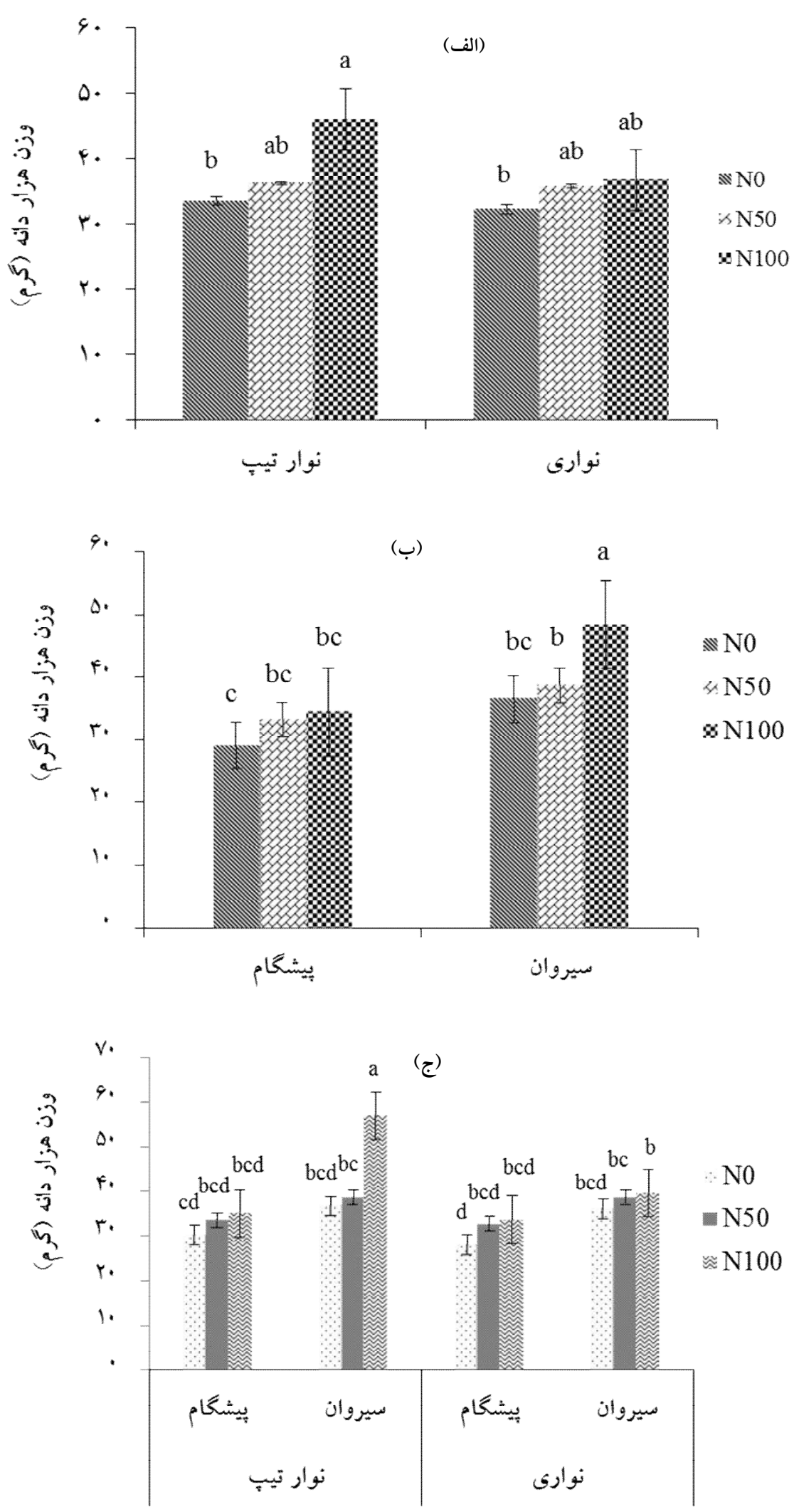

شكل r. اثر متقابل: الف) روش آبيارى و كود، ب) كود و رقم و ج) روش آبيارى، كود و رقم بر وزن هزار دانه

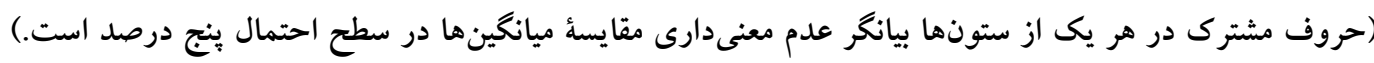




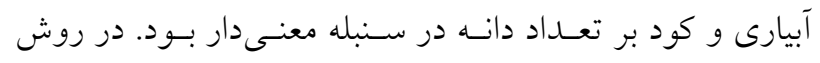

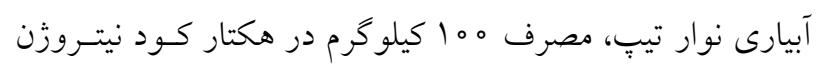

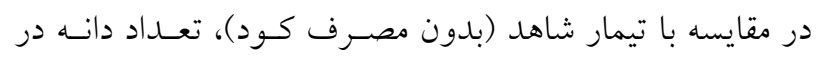

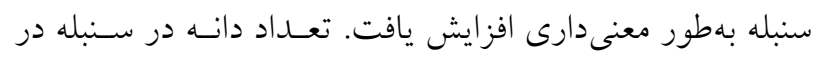

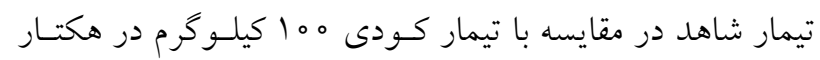

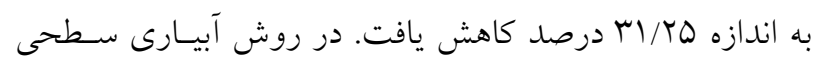

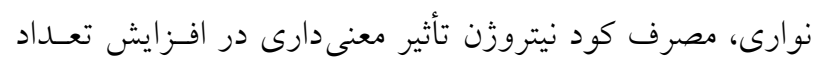
دانه در سنبله نداشت و تعداد دانه در سنبله در همــه تيمارهـاى

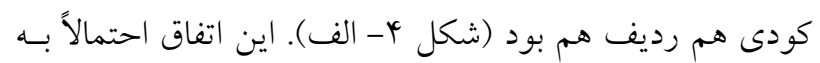

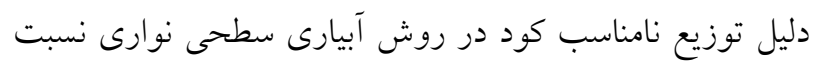

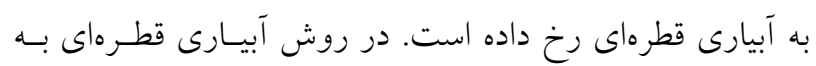

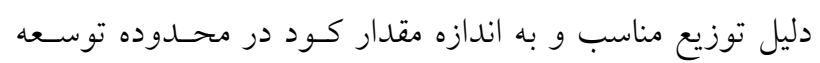

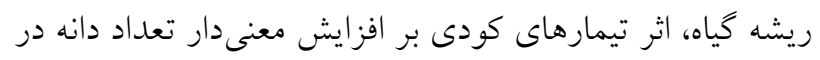

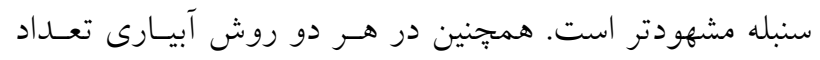
دانه در سنبله در تيمار بدون كود مشابه بود. تعداد دانه در سنبله

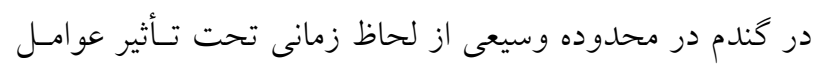

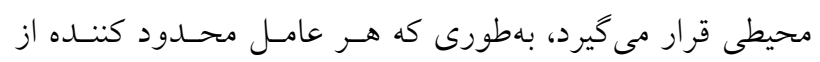

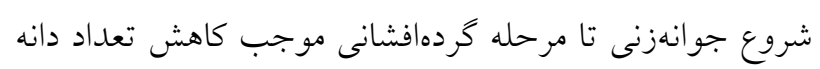

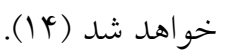

بررسى اثر متقابل روش آبيارى و رقم بر تعداد دانه در سنبله

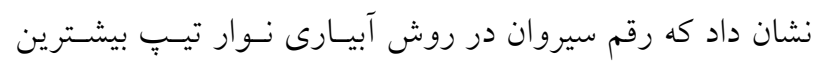

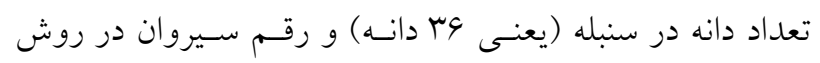
آبيارى نوارى كمترين تعداد دانه در سنبله (يعنى الب دانه) را دارا

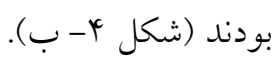
بررسى اثر متقابل كود و رقم بر تعداد دانسه در سـنبله نشـان

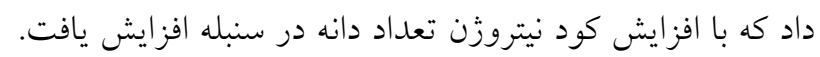

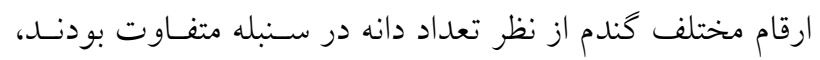

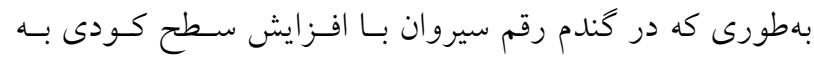
ها ميلو گرم در هكتار بيشترين تعـداد دانـه در ســبله در بـين تيمارهاى مورد آزمايش مشـاهده شــد. كمتـرين تعـداد دانـه در سنبله نيز مربوط به تيمار شاهد (بدون كود) و رقم گندم بيشگام

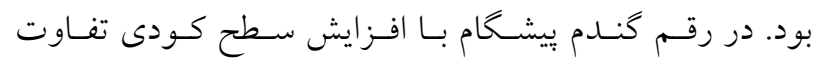

همجنِنين نشان داد كه بين تيمـار شـاهد (بـدون كـود) و سـطح

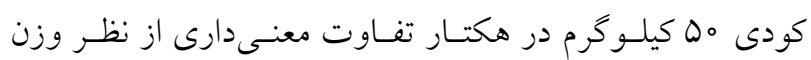

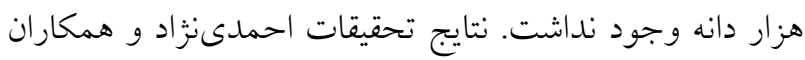

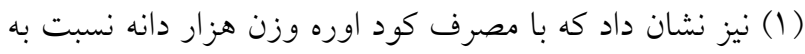

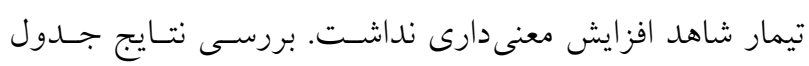

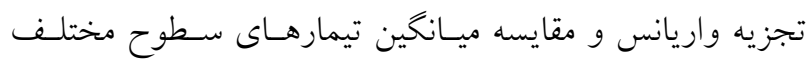

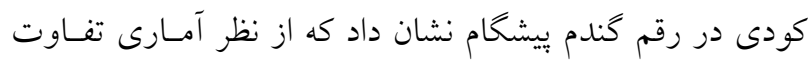

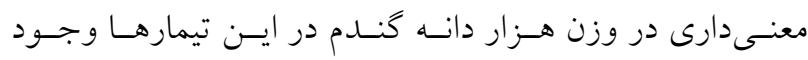

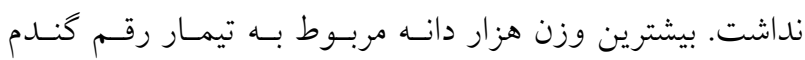

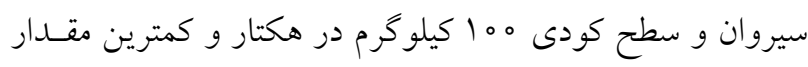

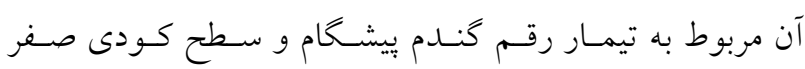

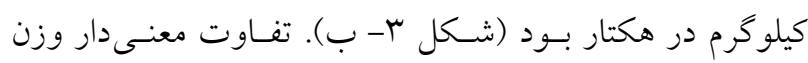

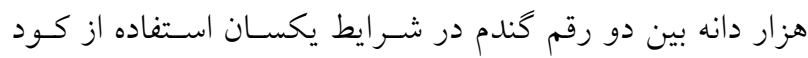

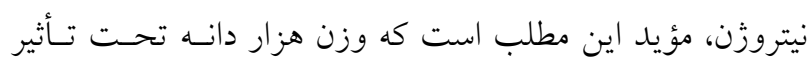
زنتيك نيز است.

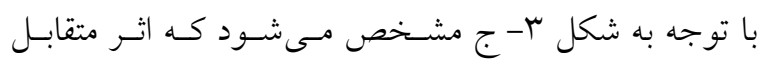
روش آبيارى، كود و رقم بر وزن هزار دانه معنى دار بود. با تغيير

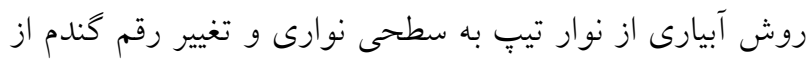

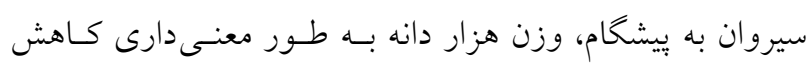

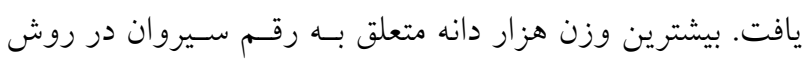

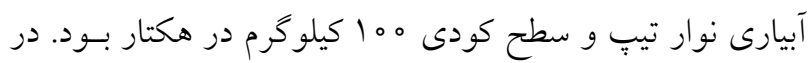

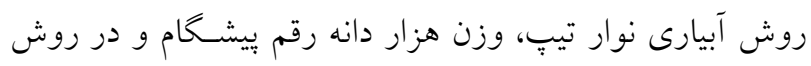

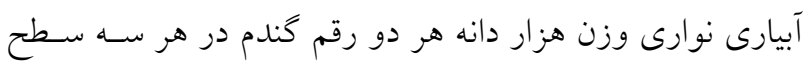

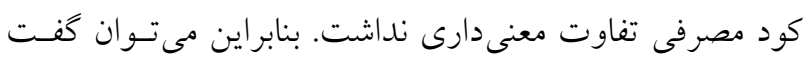
تأثير روش آبيارى در اثر بخشى كود مصرفى بسـيار مـؤثر بــوده

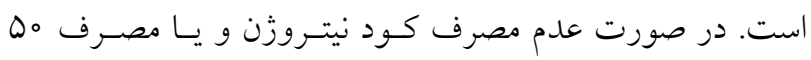

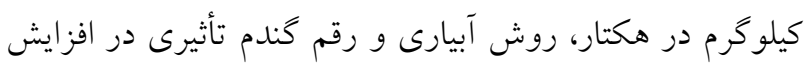
معنى دار وزن هزار دانه ندارند.

تعداد دانه در سنبله تعداد دانه در سنبله يكى از اجزاى مهم عملكرد اقتصادى است.

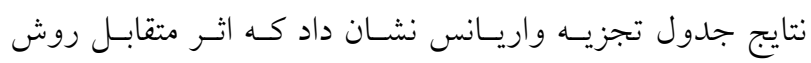



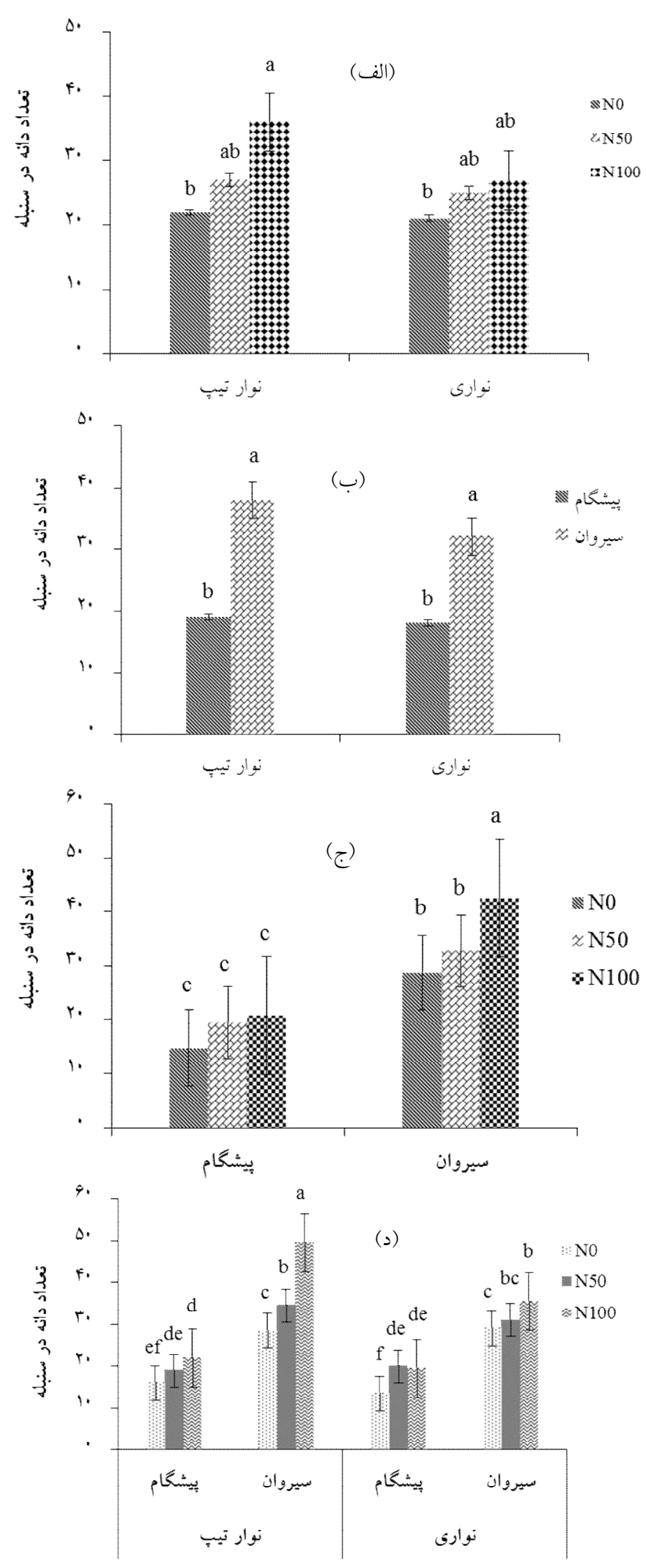

شكل f. اثر متقابل: الف) روش آبيارى و كود، ب) روش آبيارى و رقم، ج) كود و رقم و د) روش آبيارى، كود و رقم بر تعداد دانه در سنبله

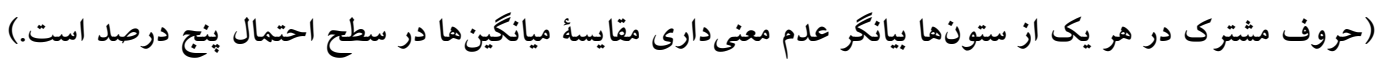




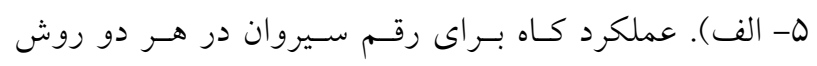

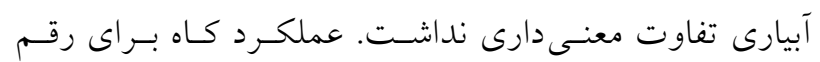

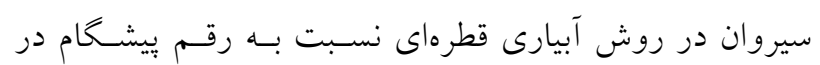

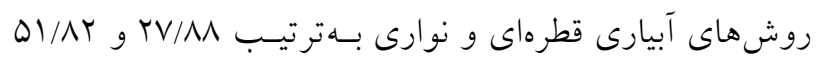
درصد افزايش نشان داد.

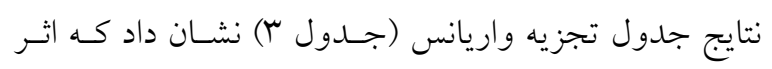

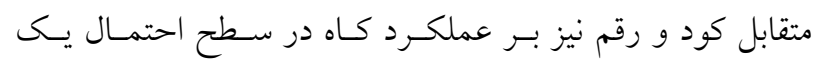

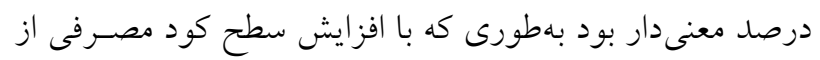

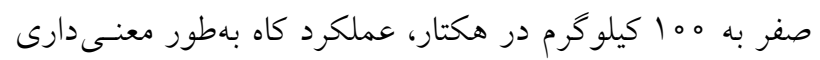

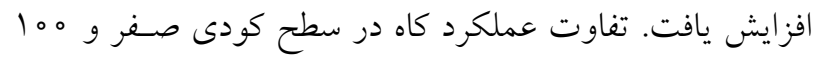

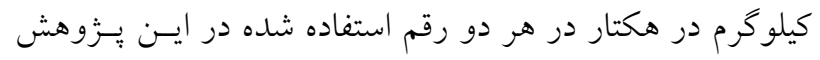

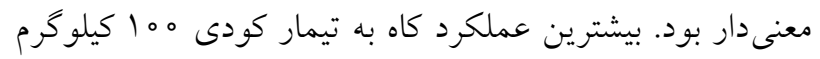

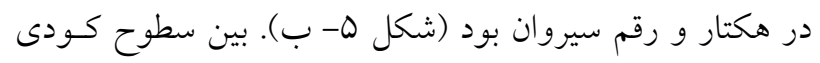
صفر و 00 كيلوكرم در هكتار در هر دو رقم ييشگام و سـيروان

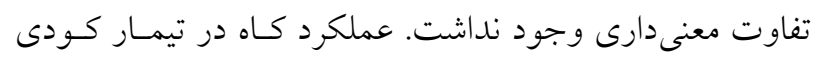

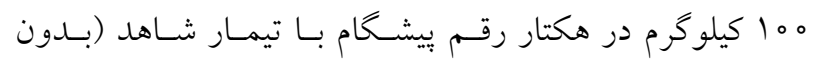

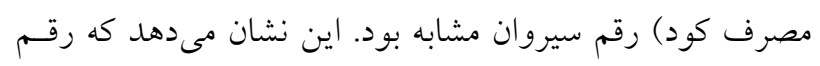

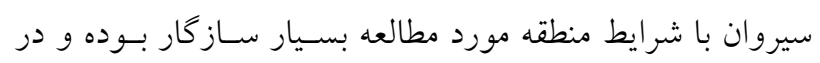

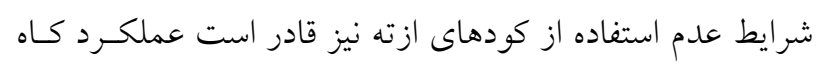

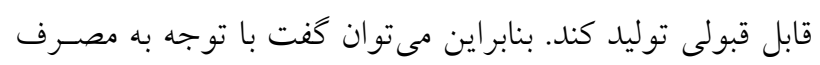

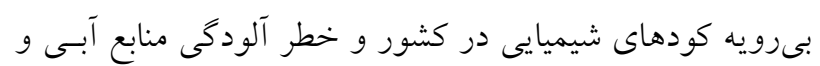

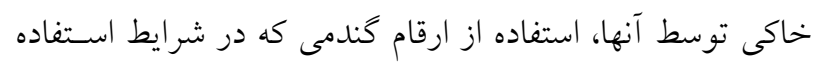

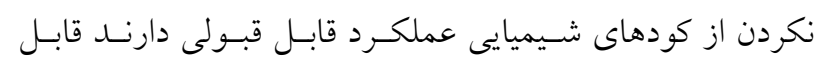

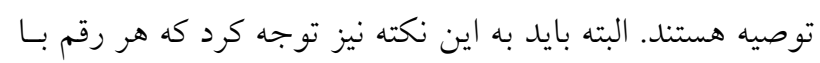
توجه به شر ايط اقليمى موجود در هر منطقه، عملكرد متفاوتى از

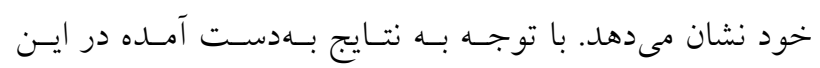

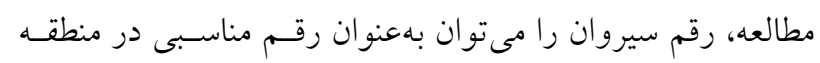

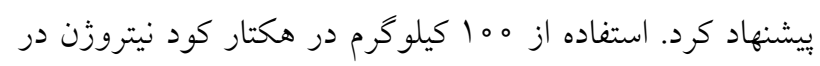

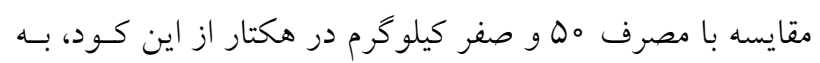

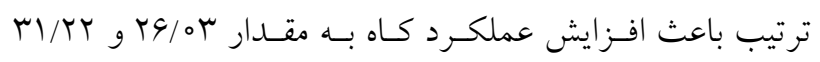

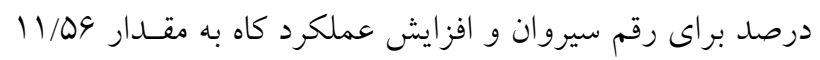

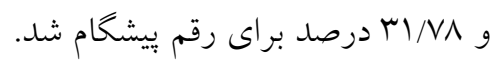

معنسى دارى بـين تعـداد دانسه در ســبله در تيمارهـاى مختلــف مشاهده نشد. اما در رقم كندم سيروان بين تيمار شـاهد (بـدون

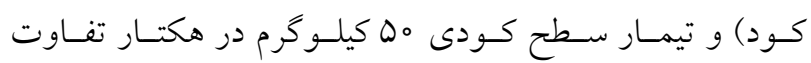

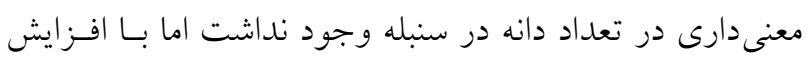

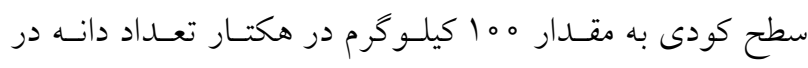

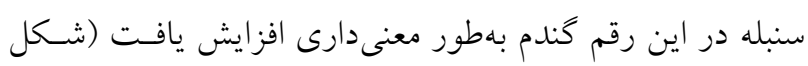

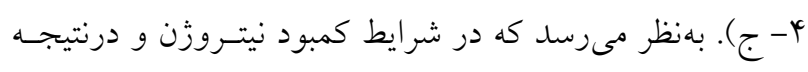

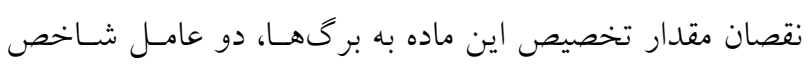

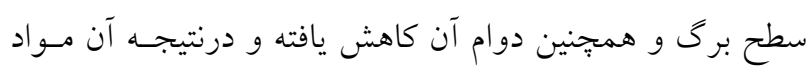

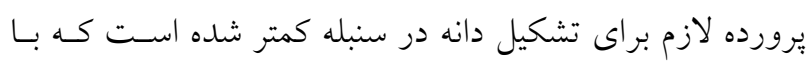

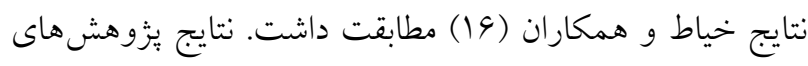

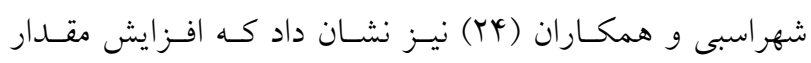

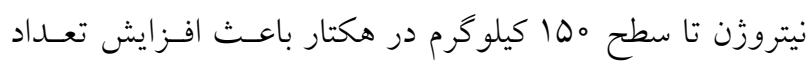

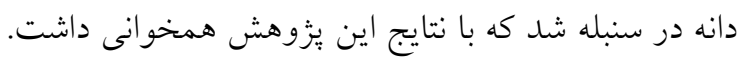

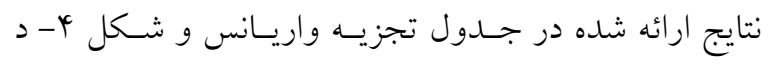

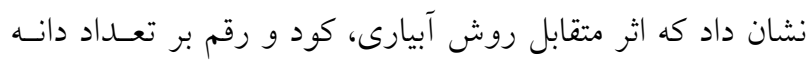

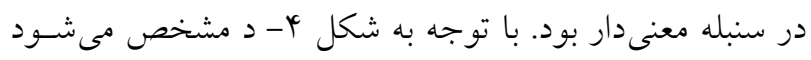

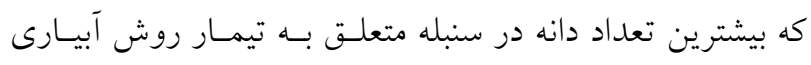

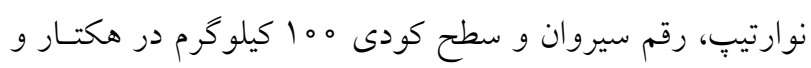

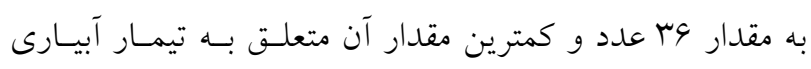

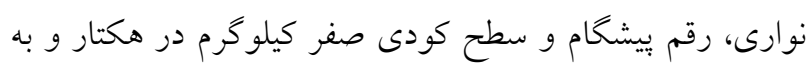

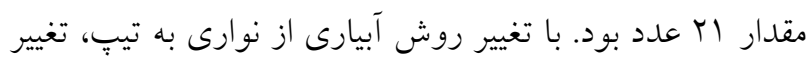

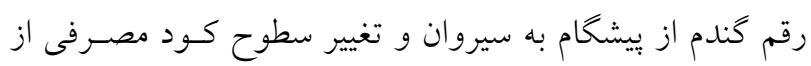

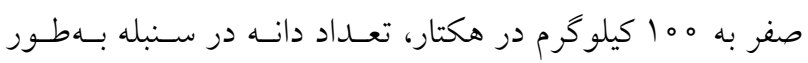

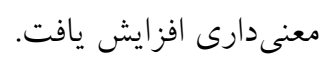

عملكرد كاه

مقايسه ميانخين اثر متقابل روش آبيارى و رقم نشان داد كه بـاـ

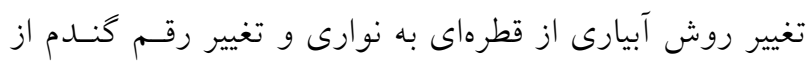

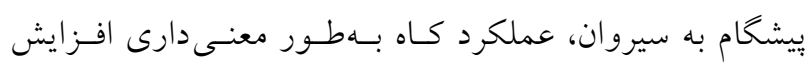

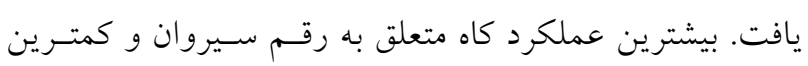

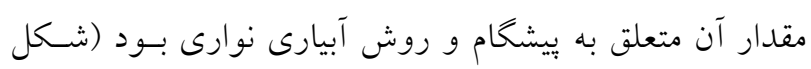



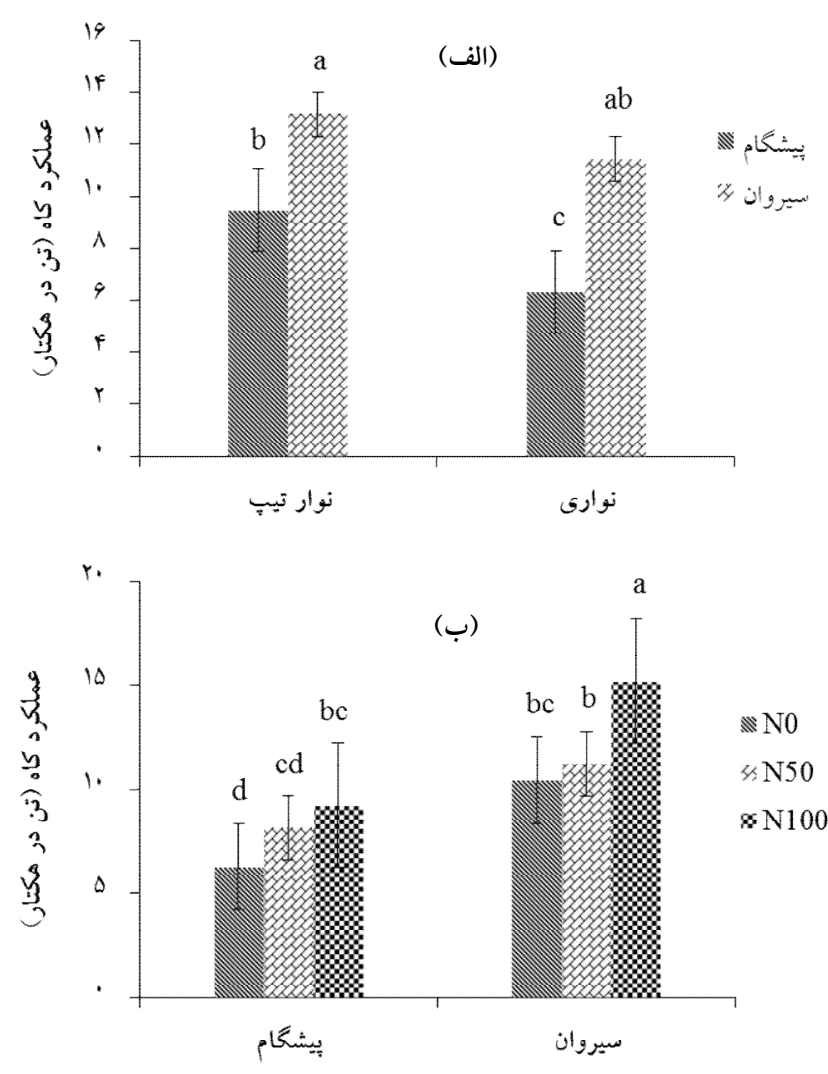

شكل ه. اثر متقابل: الف) روش آبيارى و رقم و ب) كود و رقم بر عملكرد كاه

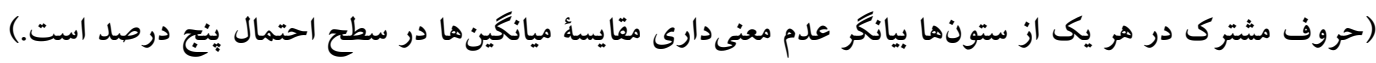

داراى شاخص برداشت بالايى هستند، مىتو انند كربوهيدراتهاى

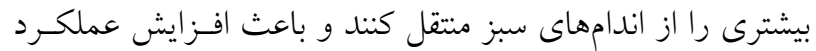
شوند (Y) (T). بنابراين بهنظر مىرسد در رقم سيروان نسبت به رقـم يشيُام درصد بيشترى از ماده خشك ذخيره شده به دانهها انتقـال

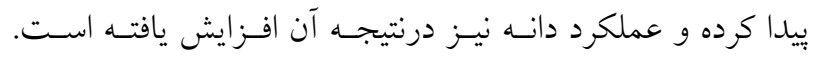

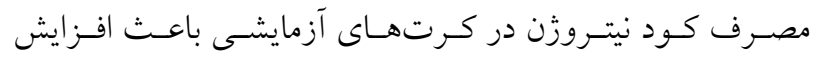

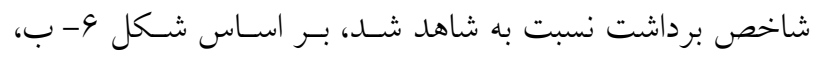

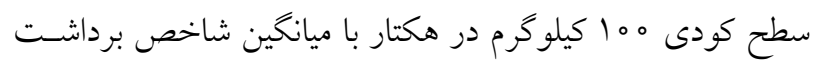

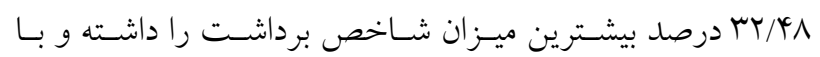

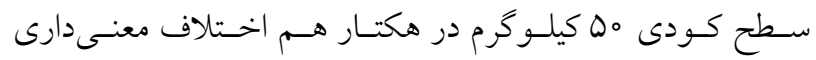

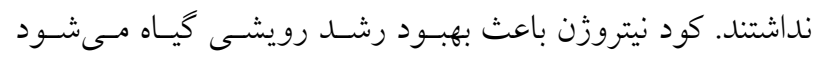

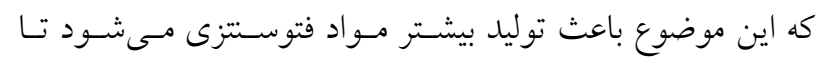
در مرحله رشد و نمو دانه، به توليد دانه اختصاص يابد و درنتيجه

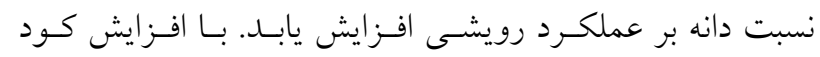

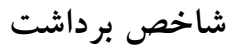

مقايسه ميانخين اثــر متقابـل روش آبيـارى و رقـمم بـر شــاخص برداشت نشان داد كه بين شاخص برداشت دو رقم كندم استفاده

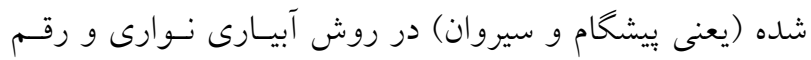

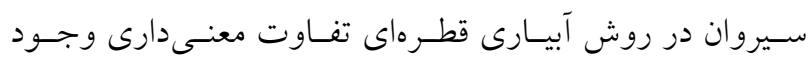

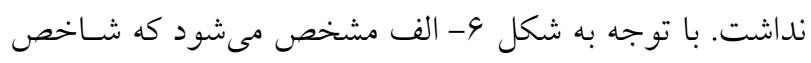

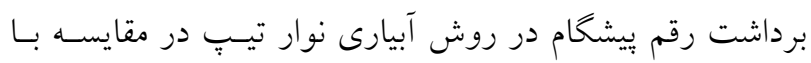
تيمارهاى ديكر كمتر بود.

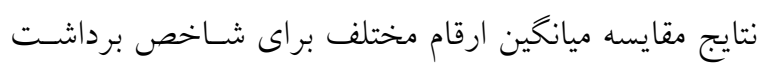

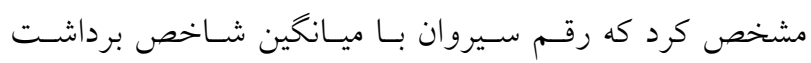

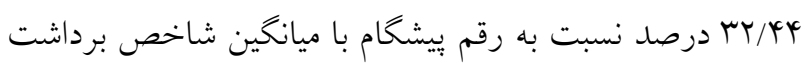
TV/N

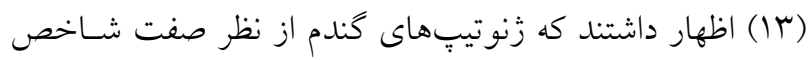

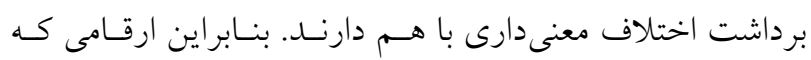



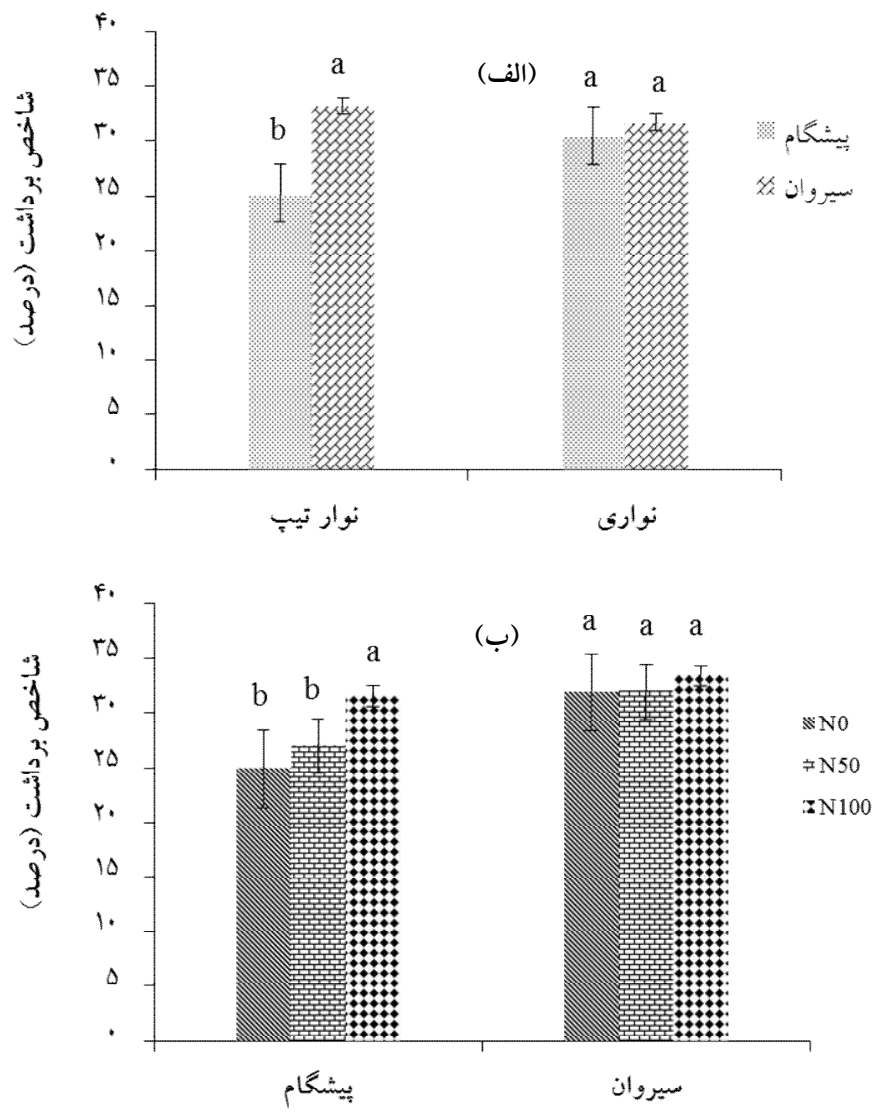

شكل و. اثر متقابل روش آبيارى و رقم (الف) و كود و رقم (ب) بر شاخص برداشت

(حروف مشترى در هر يك از ستونها بيانگر عدم معنىدارى مقايسهُ ميانگينها در سطح احتمال ينج درصد است.)

جدول f. مقايسه ميانخين اثرات ساده عامل روشهاى مختلف آبيارى، سطوح مختلف نيتروزن و رقم بر صفات مورفولوزيكى كندم

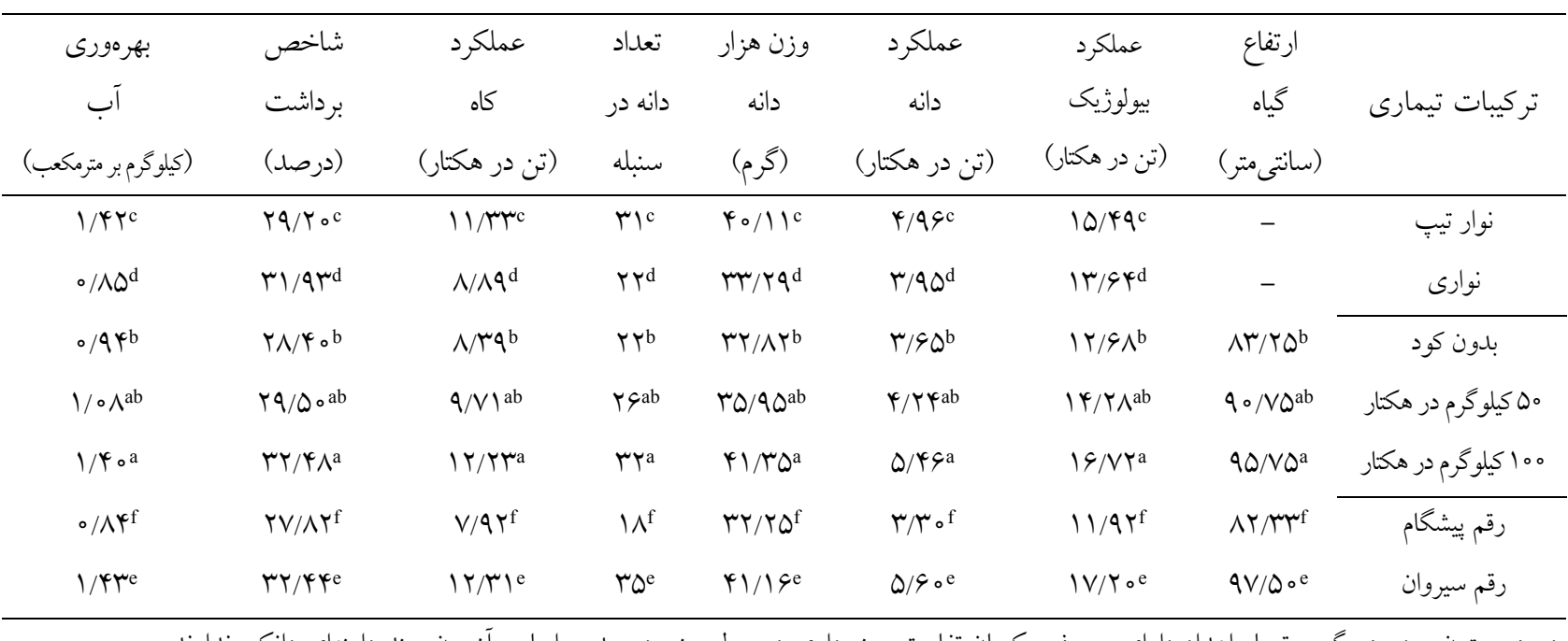

در هر ستون و در هر گروه تيمار اعداد داراى حروف يكسان تفاوت معنىدارى در سطح ينج درصد بر اساس آزمون جند دامنهاى دانكن ندارند. 
مقايسه ميانخين اثر متقابل روش آبيارى و رقم بر بهـرهورى آب

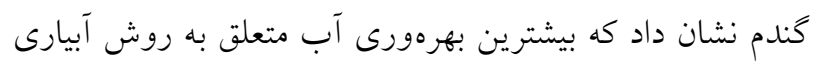

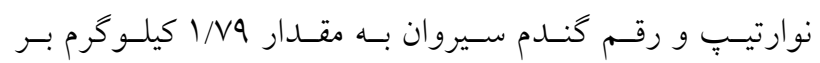

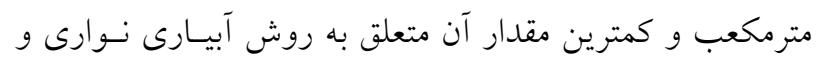

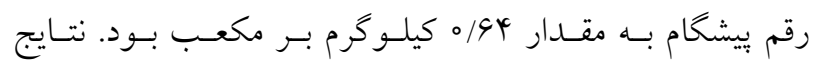

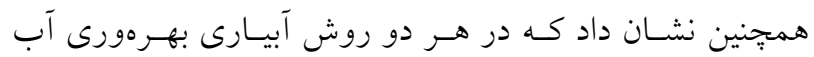

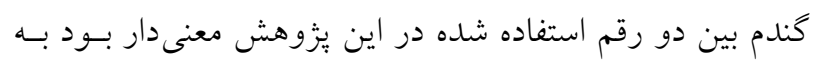

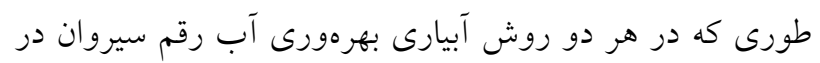

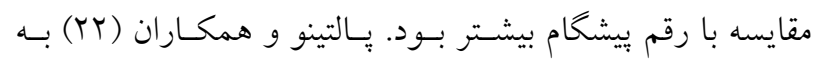

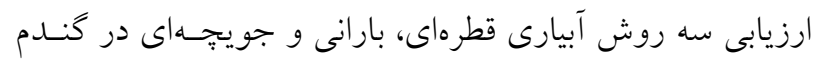

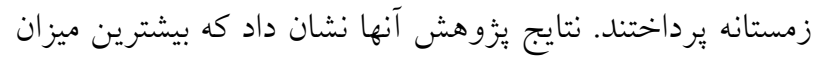

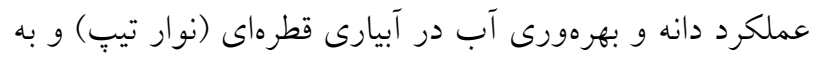

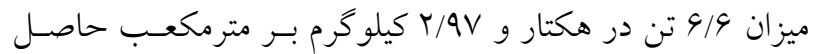

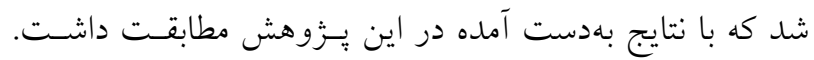

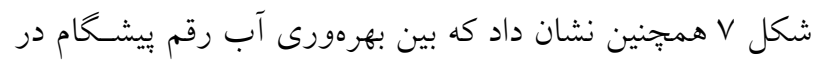

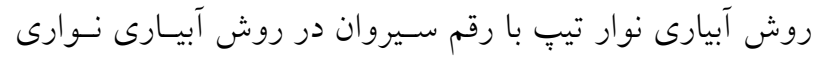

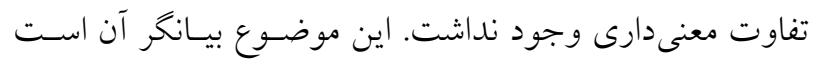

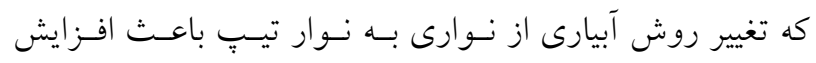
معنى دار بهرهورى آب شده است. قدمى فيروزآبادى و همكـاران

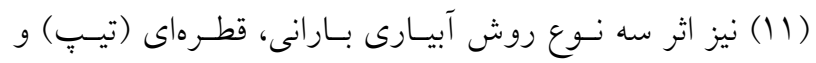

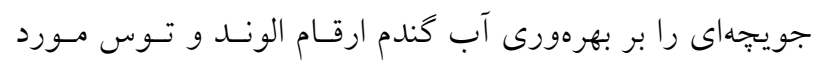

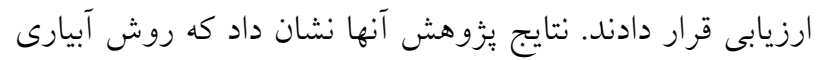

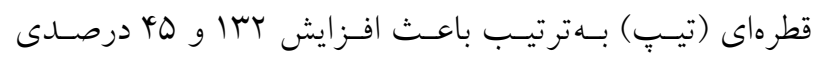

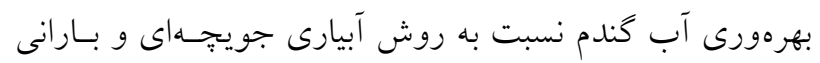

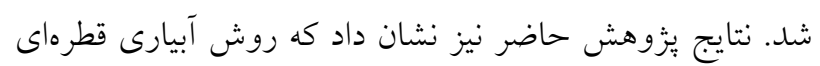

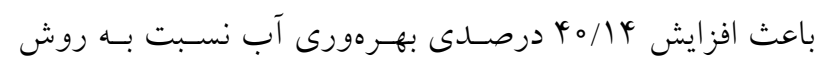
آبيارى نوارى شد.

\section{نتيجه گيرى كلى}

در اين يثزوهش اثر روش آبيارى و كود نيتروزن بر عملكرد دانسه

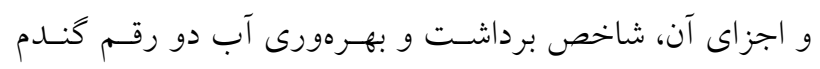

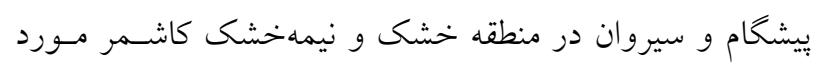

نيتروزن از 0ه كيلوكرم در هكتار بـه ه ما كيلـوكرم در هكتـار،

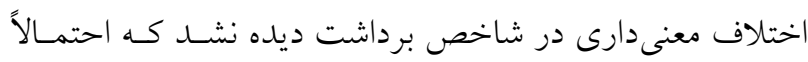

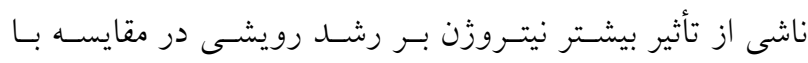

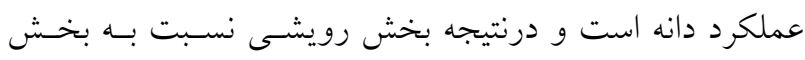

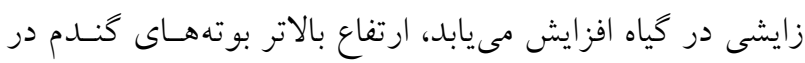

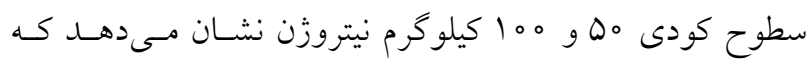

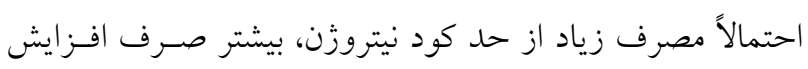

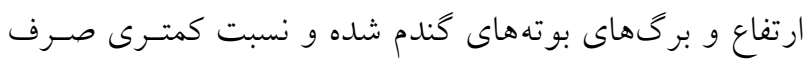

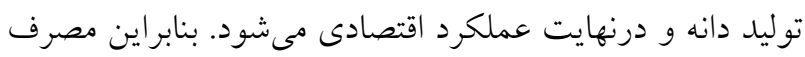

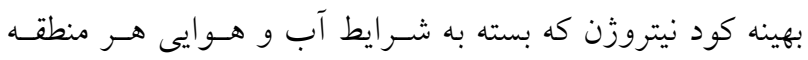

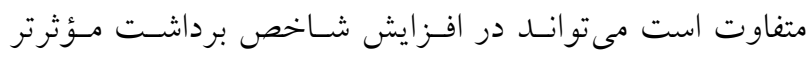
باشد.

\section{بهروورى آب}

نتايج جدول تجزيه واريانس (جدول r) نشان داد كه اثـر روش آبيارى و رقم در سطح احتمال يك درصد و اثر كود نيتروزن در

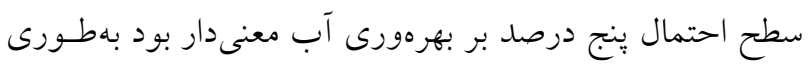

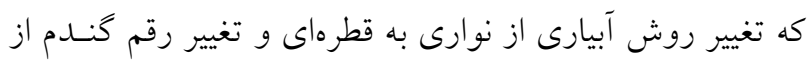

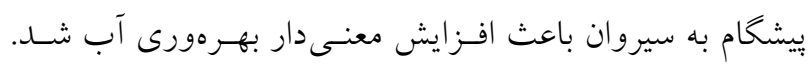

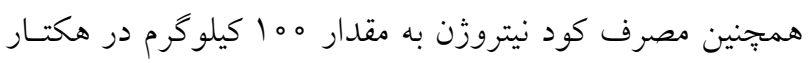
باعث افزايش معنسى دار بهـرهورى آب نسـبت بـهـ تيمـار شـاهد

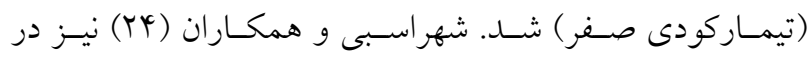

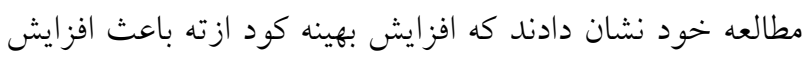

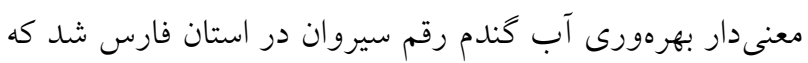

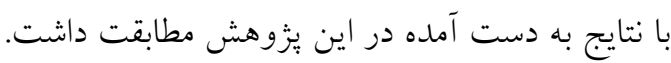

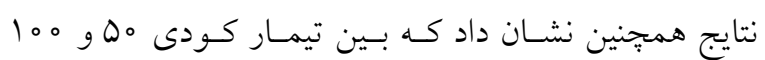

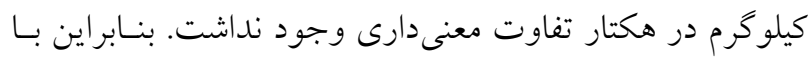

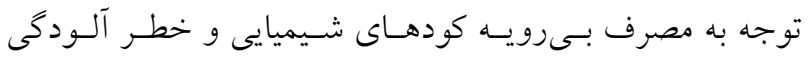

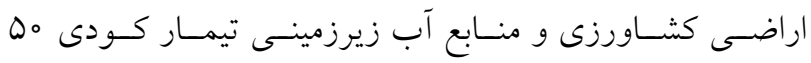

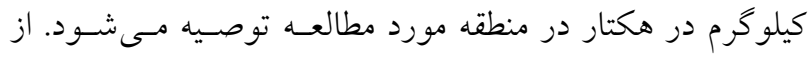

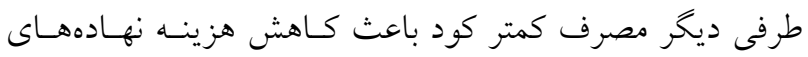
اوليه و درنتيجه سودآورى بيشتر زارعين در منطقه خواهد شدر. 


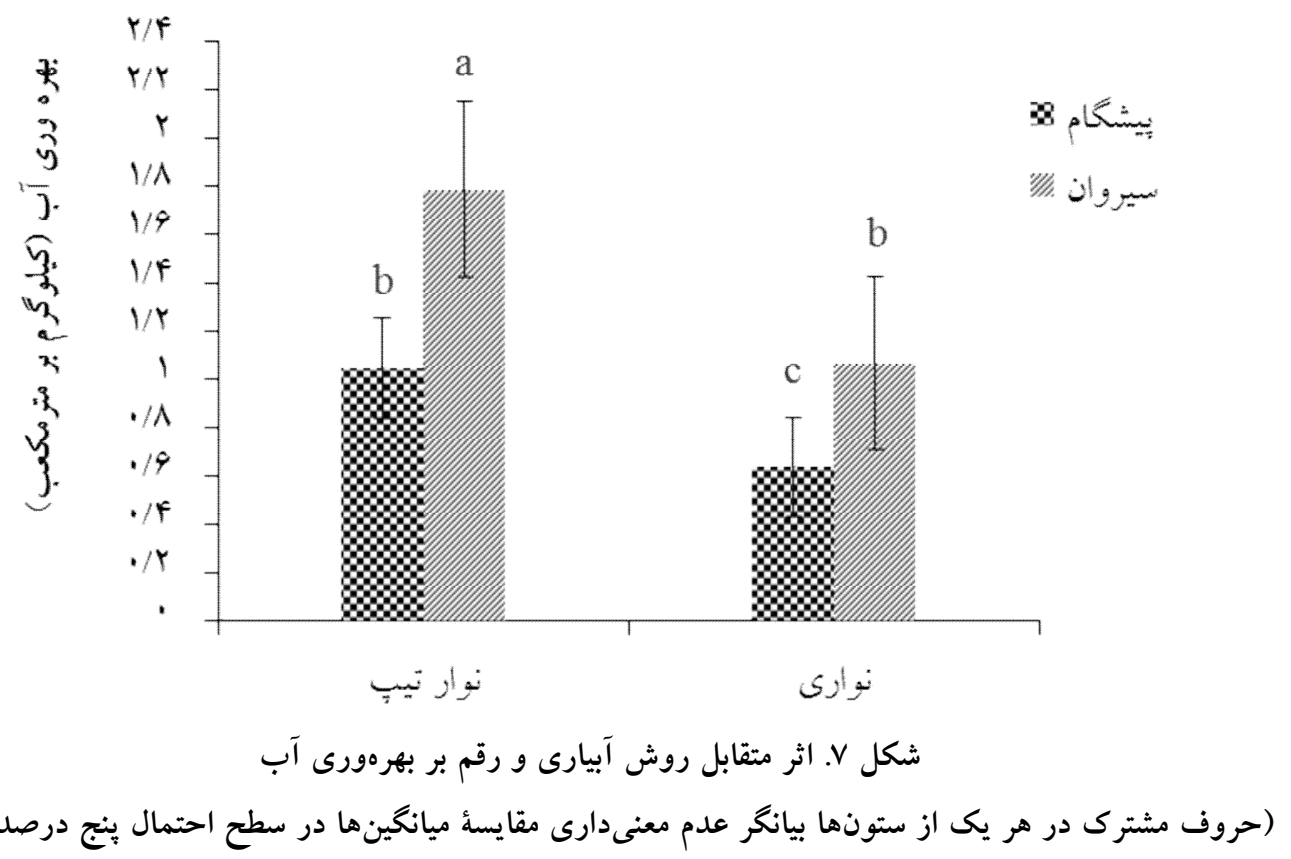

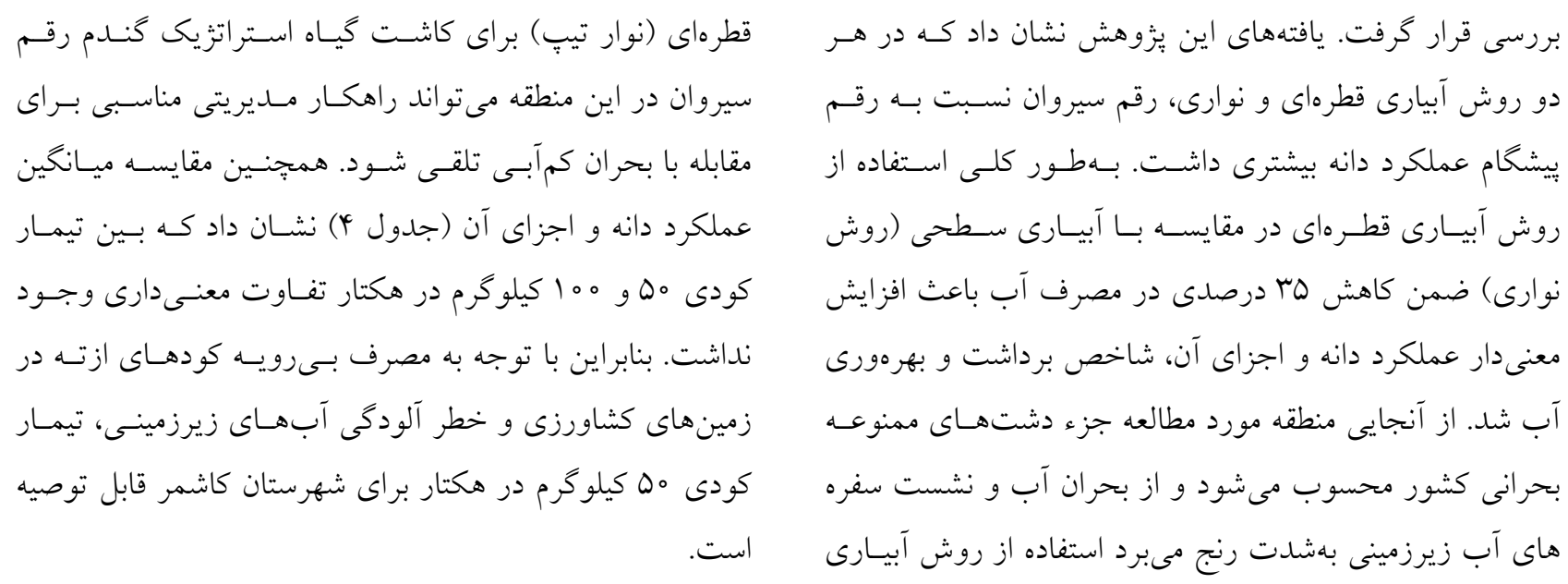

منابع مورد استفاده

1. Ahmadinejad, R., N. Najafi, N. Aliasgharzad and S. Oustan. 2013. Effect of organic and nitrogen fertilizers on water use efficiency, yield and the growth characteristics of wheat (Triticum aestivum cv. Alvand). Water and Soil Science 23(2): 177-194. (In Farsi).

2. Alizadeh, A. 2001. Principles and practices of trickle irrigation. Astan Quds Razavi Publication, Mashhad.

3. Allen, R. G., L. A. Pereira, D. Raes and M. Smith. 1998. Crop evapotranspiration. FAO irrigation and drainage paper 56, FAO, Rome.

4. Ayoub, M., S. Guertin, S. Lussier and D. L. Smith. 1994. Timing and level of nitrogen fertility effects on spring wheat yield in eastern Canada. Crop Science 34(3): 748-756.

5. Camara, K. M., W. A. Payne and P. E. Rasmussen. 2003. Long-term effects of tillage, nitrogen, and rainfall on winter wheat yields in the Pacific Northwest. Agronomy Journal 95: 828-835.

6. Emam, Y. 2012. Cereal Production. Shiraz University Press, Shiraz.

7. Emam, Y. and M. J. Seghat Aleslami. 2006. Field Crop Function: Physiology and Processes. Shiraz University Press, Shiraz. 
8. Fathi, Gh., N. Aryannia and M. R. Enayatgholizadeh. 2009. Evaluation the effect of used nitrogen and drought stress on grain yield and yield component of three wheat cultivars. Crop Physiology Journal 4: 17-29. (In Farsi).

9. Fowler, D. B. 2003. Crop nitrogen demand and grain protein concentration of spring and winter wheat. Agronomy Journal 95: 260-265.

10. Garcia, R. L. 1979. Foliar fertilization on soybean during the seed filling period. Agronomy Journal 63: 653-660.

11. Ghadami Firouzabadi, A., M. Chichi and S. M. Seyedan. 2017. Effects of different irrigation systems on yield, some agronomic traits, and water productivity of different wheat genotypes and their economic assessment in Hamedan. Journal of Water Research in Agriculture 31(2): 139-149. (In Farsi).

12. Gharineh, M. H. and H. Nadian. 2011. Sustainable Agriculture Practices. Chamran University Press, Ahvaz.

13. Jalal-Kamali, M. R. and H. R. Sharifi. 2011. Variation in developmental stages and its relationships with yield and yield components of bread wheat cultivars under field conditions. Journal of Seedlings and Seeds of Racial 89(1): 457-461. (In Farsi).

14. Kafi, M., M. Jafarnezhad and M. Jami Alahmadi. 2005. Ecology, Physiology and Wheat Yield Estimation. Ferdowsi University of Mashhad Press, Mashhad.

15. Keykhaei, F. and N. Ganjikhorramdel. 2016. Effect of deficit irrigation in corrugation and border methods on yield and water use efficiency of wheat cv. Hamoon. Water Research in Agriculture 30(1): 1-11. (In Farsi).

16. Khayat, S. H., M. Mojadam and M. Alavi Fazel. 2014. Effect of nitrogen rates on grain yield and nitrogen use efficiency of durum wheat genotypes in Khouzestan. Crop Physiology 6(21): 103-113. (In Farsi).

17. Kijne, J. W., B. Randolph and D. J. Molden. 2003. Water Productivity in Agriculture: Limits and Opportunities for Improvement. CABI Publishing, London.

18. Malakouti, M. and M. Homaee. 2005. Soil Fertilities in Arid and semi-Arid Regions, Problems and Resolves. Tarbiat Modares University Press, Tehran.

19. McMaster, G. S., R. M. Aiken and D. C. Nielsen. 2000. Optimizing wheat harvest cutting height for harvest efficiency and soil and water conservation. Agronomy Journal 92: 1104-1108.

20. Omidinasab, D., M. H. Gharineh, A. Bakhshandeh, M. Sharafizade, A. Shafeinia and A. Saghali. 2015. The effect of seeding rates and nitrogen fertilizer on yield and yield components of wheat cultivars in corn residue (no tillage). Iranian Journal of Field Crops Research 13(3): 598-610. (In Farsi).

21. Omidinasab, D., M. H. Gharineh, A. Bakhshandeh, M. Sharifizadeh and A. R. Shafeinia. 2016. Effect of nitrogen fertilizer and seed density in direct planting of two wheat varieties. Weed Ecology 2(2): 135-150. (In Farsi).

22. Paltineanu, I. C., C. Negrila, C. E. Negrila, M. Craciun and I. Craciun. 1994. Long term trials on irrigated field crops in semi-arid area of Romania. Romanian Agricultural Research 1: 85-92.

23. Raun, W. R. and G. V. Johnson. 1999. Improving nitrogen use efficiency for cereal production. Agronomy Journal 91: 357-363.

24. Shahrasbi, S., Y. Emam, A. Ronaghi and H. Pirasteh-Anosheh. 2016. Effect of drought stress and nitrogen fertilizer on grain yield and agronomic nitrogen use efficiency of wheat (Triticum aestivum L. cv. Sirvan) in Fars Province, Iran conditions. Iranian Journal of Crop Sciences 17(4): 349-363. (In Farsi).

25. Shahsavari, N. and M. Saffari. 2006. The effect of different levels of nitrogen on the function and elements of the varieties of wheat in Kerman. Pajouhesh and Sazandegi 66: 82-87. (In Farsi).

26. Sharma, S. K., P. K. Mishra., R. Panse and G. Jamliya. 2018. Effect of irrigation methods on yields attributes and water productivity of wheat in vertisol of Betwa river basin commands of Vidisha District of M.P, India. International Journal of Current Microbiology and Applied Sciences 7(8): 2670-2673.

27. Tadayon, M. R. and Y. Emam. 2007. Effect of supplemental irrigation and nitrogen on morphologic responses and grain yield of two wheat cultivars under dry land conditions in Fars province. Scientific Journal of Agriculture 30(2): 53-69. (In Farsi).

28. Vafapour, M., S. H. Jahanbeen, A. Yadavi and M. H. Fallah Heki. 2011. Effect of foliar application of Phosphorus and water deficit on yield and yield components of winter wheat (cultivar Alvand). Crop Production and Processing 1(1): 67-80. (In Farsi). 


\title{
Investigation the Effect of Changing the Irrigation Method on the Harvest Index and Water Productivity of Two Wheat Cultivars with the Use of Nitrogen Fertilizer
}

\author{
M. Mokari ${ }^{1 *}$ \\ (Received: February 25-2020; Accepted: July 11-2020)
}

\begin{abstract}
Optimal use of water resources seem to be necessary due to climate change and the recent drought conditions. One of the most important and effective management strategies is increasing water productivity in agriculture. Irrigation method and the use of different levels of nitrogen fertilizer are the effective factors in increasing the water productivity. Therefore, this study was conducted to investigate the effect of the irrigation method and nitrogen fertilizer on the harvest index and water productivity of two wheat cultivars with 36 treatments as a split-split plot based on a completely randomized design with three replications in the research farm of Natural Resources and Agricultural Research Center of Kashmar, during the 2018-2019 time period. The treatments were two irrigation methods including end blocked border and drip irrigation (tape) as the main plots, three levels of the nitrogen fertilizer from urea source including 0,50 and $100 \mathrm{~kg} / \mathrm{ha}$ as the sub plots and two cultivars of wheat including Pishgam and Sirvan as the sub-sub plots. The results showed that by changing the border irrigation method to the drip irrigation (tape) method, the harvest index and water productivity were increasesignificantly. The results also showed that grain yield and its components, including harvest index and water productivity, had no significant difference in 50 and $100 \mathrm{~kg} / \mathrm{ha}$ nitrogen levels. On the other hand, grain yield and its components, harvest index and water productivity, were significantly higher in the Sirvan cultivar rather than the Pishgam one $(\mathrm{P}<0.01)$. According to the results obtained from this study, the drip irrigation method, $50 \mathrm{~kg} / \mathrm{ha}$ nitrogen level and Sirvan cultivar could be recommended for the study region.
\end{abstract}

Keywords: Grain yield, Water productivity, Harvest index.

1. Water and Science Engineering Department, Kashmar Higher Education Institute, Iran.. Corresponding author, Email: mehdimokari@gmail.com 